\title{
WestVirginiaUniversity
}

THE RESEARCH REPOSITORY @ WVU

Graduate Theses, Dissertations, and Problem Reports

2005

\section{Prediction of forage intake and production of steers in a winter forage system}

\author{
Taryn Romanczak \\ West Virginia University
}

Follow this and additional works at: https://researchrepository.wvu.edu/etd

\section{Recommended Citation}

Romanczak, Taryn, "Prediction of forage intake and production of steers in a winter forage system" (2005). Graduate Theses, Dissertations, and Problem Reports. 2205.

https://researchrepository.wvu.edu/etd/2205

This Thesis is protected by copyright and/or related rights. It has been brought to you by the The Research Repository @ WVU with permission from the rights-holder(s). You are free to use this Thesis in any way that is permitted by the copyright and related rights legislation that applies to your use. For other uses you must obtain permission from the rights-holder(s) directly, unless additional rights are indicated by a Creative Commons license in the record and/ or on the work itself. This Thesis has been accepted for inclusion in WVU Graduate Theses, Dissertations, and Problem Reports collection by an authorized administrator of The Research Repository @ WVU. For more information, please contact researchrepository@mail.wvu.edu. 
Prediction of Forage Intake and Production of Steers in a Winter Forage System

By:

Taryn Romanczak

Thesis submitted to the Davis College of Agriculture, Forestry and Consumer Sciences

at West Virginia University in partial fulfillment of the requirements for the degree of

Master of Science

In

Ruminant Nutrition

Approved by

Eugene E. Felton, Committee Chairperson

William Bryan

P. Brett Kenney

Division: Animal and Veterinary Science

Morgantown, West Virginia 26505

2005

Keywords: steers, pasture finishing, predicting intake, intake markers, winter forage systems 


\begin{abstract}
Prediction of Forage Intake and Production of Steers in a Winter Forage System
\end{abstract}

\title{
Taryn Romanczak
}

Currently there are no means to accurately predict intake in grazing animals. Two experiments were conducted to determine and validate the use of intake markers in grazing ruminants as well as to compare performance of steers in winter forage systems. Six Angus-Hereford steers were halter and fecal harness broke. Entities commonly found in forages and used as markers were evaluated. Experiment 1 was conducted during the summer 2004, at the West Virginia University Livestock Farm, using animals in a confined area. Steers were fed timothy or orchardgrass hay chopped to fine or coarse lengths. Experiment 2 was conducted at the Reedsville Experimental Farm, during the winter, 2004-05, but with animals in a grazing situation. Experiment 2 also examined four different forage systems for wintering steers and compared animal performance using ultrasonography and animal weight changes. 


\section{ACKNOWLEDGMENTS}

I would like to express my sincere thanks to my graduate advisor, Dr. Gene Felton, for his patience, understanding, guidance, supervision, and suggestions throughout this research project and for the time devoted to the preparation of this manuscript. I would also like to thank the other members of my committee- Drs. W. Bryan and P. B. Kenney- for their advice and assistance throughout this study. I would like to express my appreciation to research assistant Eric Nestor for all his help with every aspect of this research. I would also like to thank Eric for his patience with me, dedicated help with sample collection and management of the animals, and for always being there to help when I needed it. I wish to thank everyone, especially work study Neil Bumgarner, for trekking out to the Reedsville farm in the worst weather we had this past winter to change diapers on cows. I would like to extend thanks to Mark Satterfield and Domingo Mata for his help with various tasks with this project throughout the winter. I want to thank all the members of this research team, both animal and plant sciences, for being such a fun group of people to work with. Thank you to the Reedsville farm crew; Randy, Alan, Dave, and Eddie; for always being willing to help me, for coming out to check on me late on weekends in snow storms, and for putting in the extra effort to help out with the project. I would like to thank Tammy K. Miller and the employees of the Rumen Fermentation and Profiling Laboratory for their cooperation, assistance, and use of Tammy's labs for sample analysis. I would also like to thank Tammy for the use of her fistulated cows for sample preparation and incubations. I would also like to thank the fistualated cows for the use of their rumens! 
I wish to thank my parents, Joe and Dawn, and my sister, Krista, and her family, for being there to support, guide, and encourage me for the past two years and always being there to give an encouraging word when I thought I would never make it or could not get something done. I appreciate all the things my family has done for me throughout the years. I love you guys and I could not have done this without you. The encouragement and assistance of fellow graduate students and staff is also greatly appreciated. 


\section{TABLE OF CONTENTS}

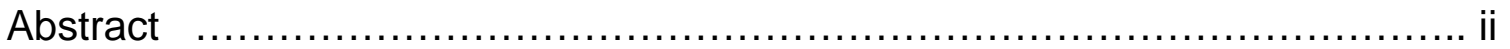

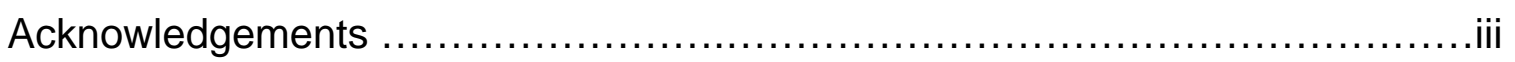

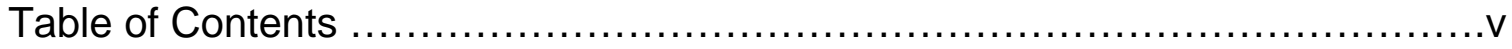

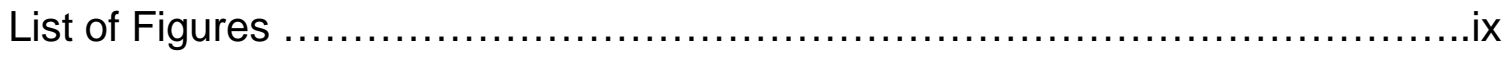

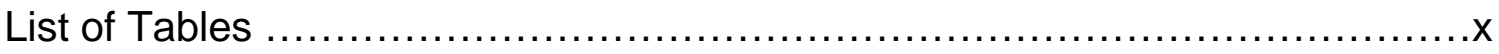

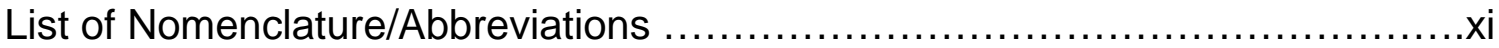

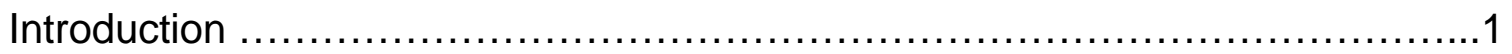

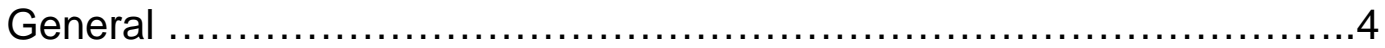

Historical Production of Cattle ....................................

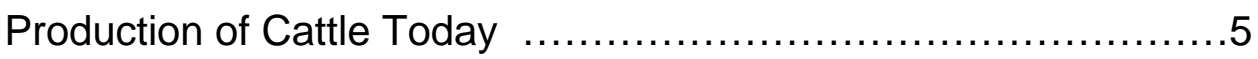

Cool Season Grasses in the Appalachain Region ........................9

Kentucky Bluegrass ............................................

General Characteristics .................................10

Potential for Stockpiling ..................................11

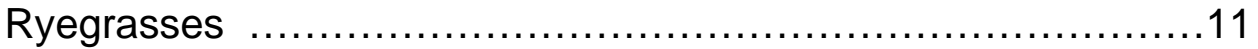

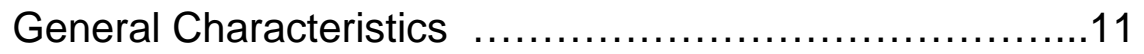

Potential for Stockpiling ...................................12

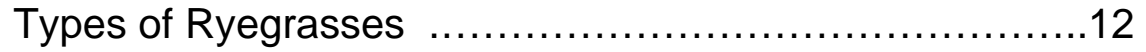

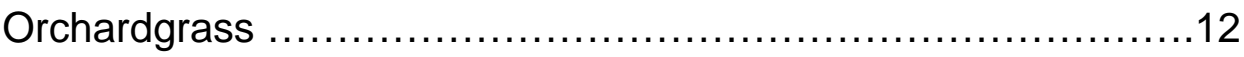

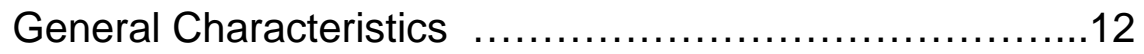

Potential for Extending the Grazing Season ...............14

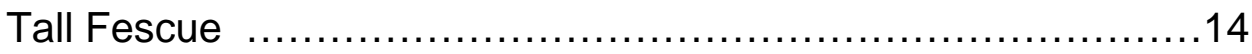

General Characteristics ................................14

Endophyte Infected Tall Fescue .........................15

Stockpiling Tall Fescue ...................................16

Smooth Bromegrass ..........................................17

General Characteristics ................................ 17

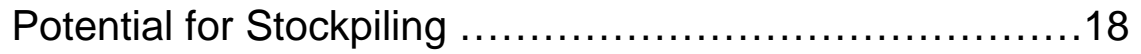




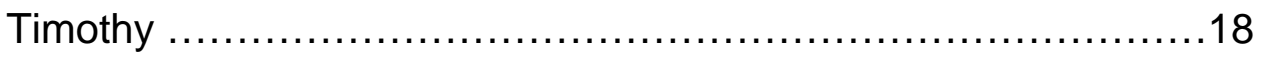

General Characteristics ................................. 18

Potential for Stockpiling .................................19

Reed Canarygrass ............................................... 19

General Characteristics .................................19

Potential for Stockpiling .................................20

Palatability and Endophyte Infection ......................20

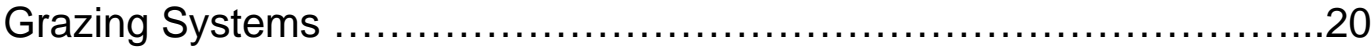

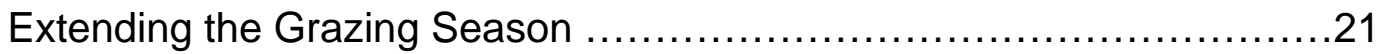

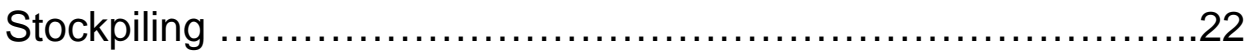

Use of Legume Mixtures for Stockpiling ........................23

Forage Systems and Animal Performance ........................24

Forage Diets with Supplementation .............................24

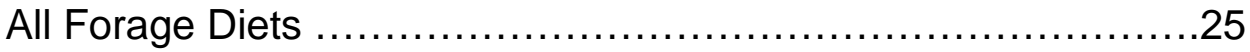

Temperature Effects on Animal Performance ....................28

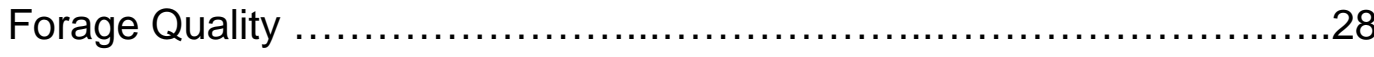

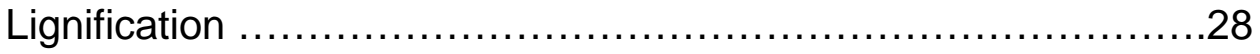

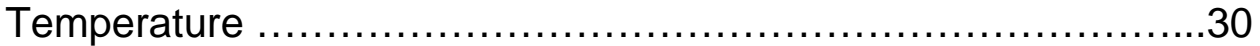

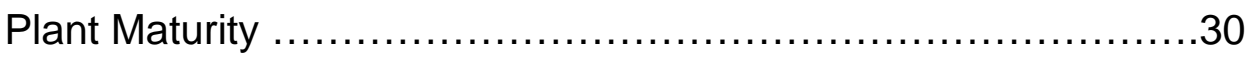

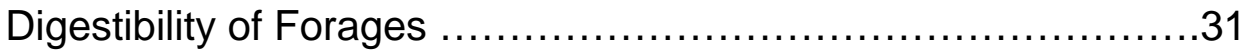

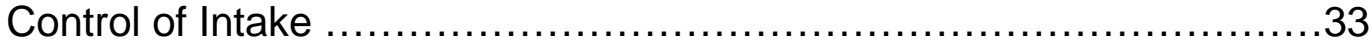

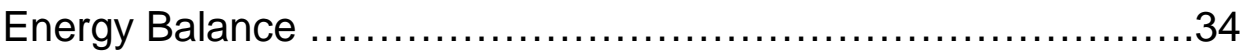

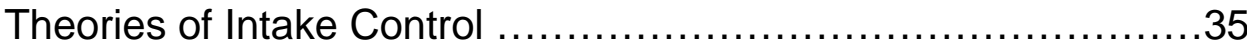

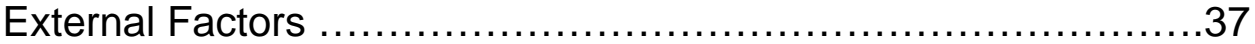

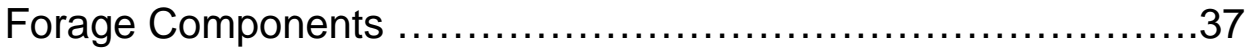

Long and Short Term Control .....................................39

Chemostatic and Metabolic Control ...............................41

Psychogenic Regulation .........................................43

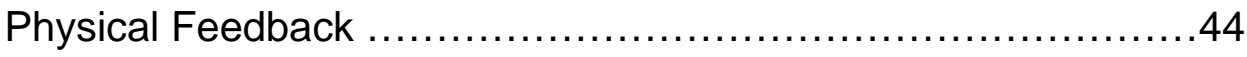

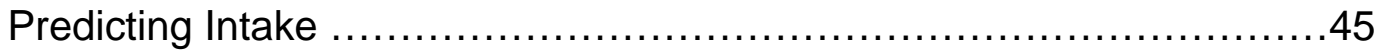

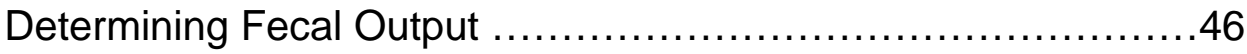


Use of Markers to Predict Intake ................................47

Marker Characteristics .....................................48

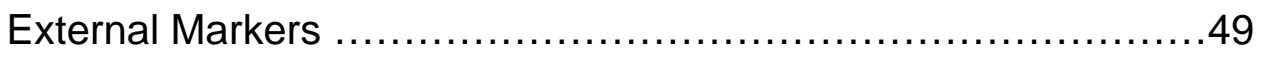

Chromic Oxide ............................................49

Rare Earth Elements ...................................50

Internal Markers ............................................. 51

Indigestible Neutral Detergent Fiber ......................51

Acid Insoluble Ash ........................................52

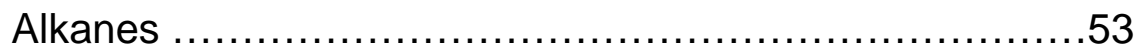

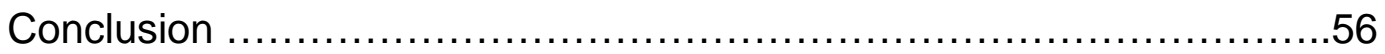

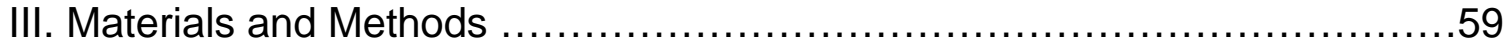

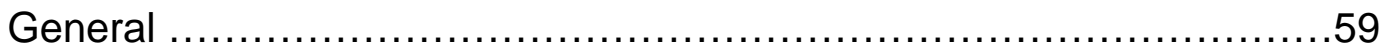

Experiment 1: Predicting Intake in a Controlled Environment .............59

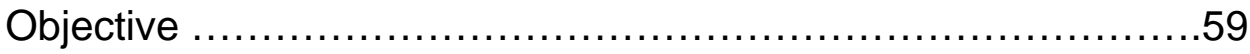

Experimental Area and Animals .................................60

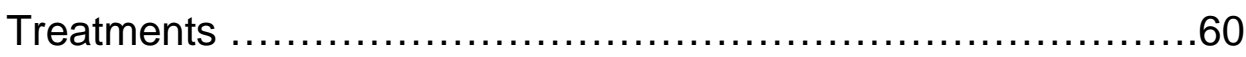

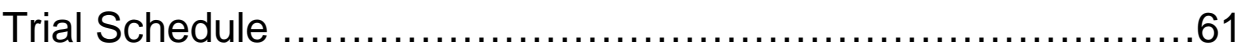

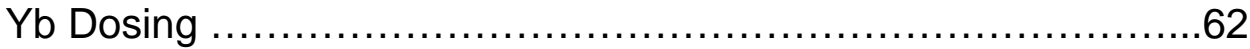

Analytical Methods .............................................. 62

Sample Preparation and Analysis .......................62

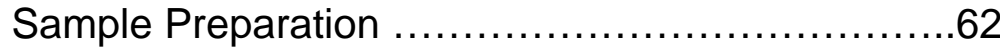

Analysis ..........................................63

Indigestible Neutral Detergent Fiber .................63

Acid Insoluble Ash .................................64

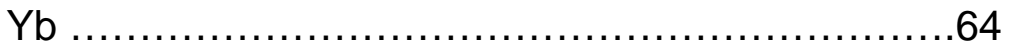

Statistical Analysis ........................................65

Experiment 2: Winter Feeding Trials: Predicting Intake in a Pasture Setting and Production of Steers in Winter Forage Systems..............65

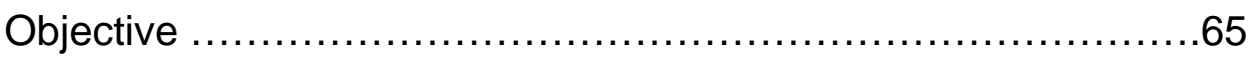

Experimental Area and Animals .................................66

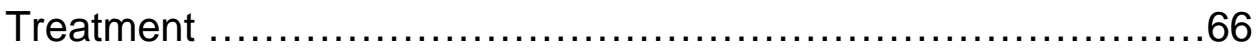


Trials and Sampling ............................................. 68

Sample Preparation and Analysis ..............................70

Statistical Analysis ............................................ 70

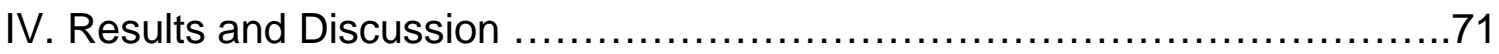

Experiment 1: Predicting Intake in a Controlled Environment ..............71

Experiment 2: Winter Feeding Trials: Predicting Intake in a Pasture

Setting and Production of Steers in Winter Forage Systems................73

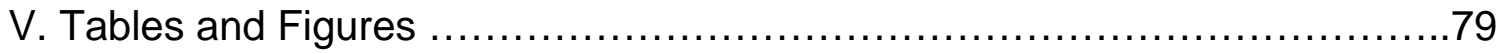

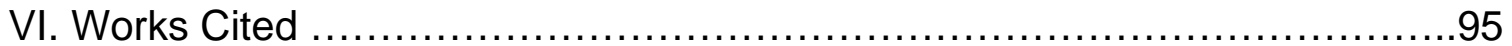

Approval of Examining Committee ............................................105 


\section{LIST OF FIGURES}

PAGE

Figure 1. Division of forage organic matter using detergents 79

Figure 2. Conceptual diagram of intake regulation based on psychogenic (1), physiological (2), and physical (3) theories of intake. Solid lines are nutrient flows and dashed lines are information or stimuli flows. The $\mathrm{X}$ indicates a nutrient flow regulation point

Figure 3. Animal characteristics affecting intake 81

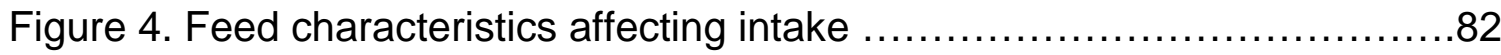

Figure 5. Management factors affecting intake $\ldots \ldots \ldots \ldots \ldots \ldots \ldots \ldots \ldots \ldots \ldots . \ldots \ldots$

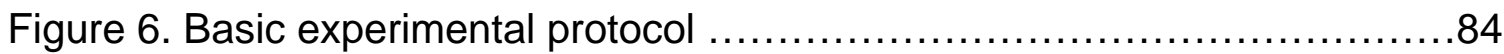

Figure 7. Average Daily Temperature (Experiment 1) $\ldots \ldots \ldots \ldots \ldots \ldots \ldots \ldots \ldots \ldots$

Figure 8. Average daily temperature (Experiment 2) $\ldots \ldots \ldots \ldots \ldots \ldots \ldots \ldots \ldots \ldots$

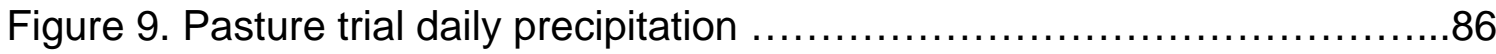

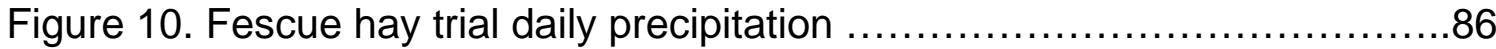

Figure 11. Orchardgrass and native hay trial daily precipitation $\ldots \ldots \ldots \ldots \ldots \ldots . \ldots 7$

Figure 12. Location of winter grazing treatments at Reedsville Experimental

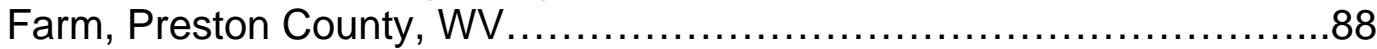

Figure 13. Fescue plot, replication 1, INDF intake as a percentage of Body weight

Figure 14. Fescue plot, replication 3, INDF intake as percentage of Body weight 


\section{LIST OF TABLES}

PAGE

Table 1. Average body weight (kgs) of steers at the beginning and

End of each trial

Table 2. Hay Analysis for Timothy Hay and Orchardgrass hay

.90

Table 3. DM, NDF, ADF, INDF, and AIA intakes as a percentage of body weight

Table 4. Average body weight (kgs) of tester steers during each trial 91

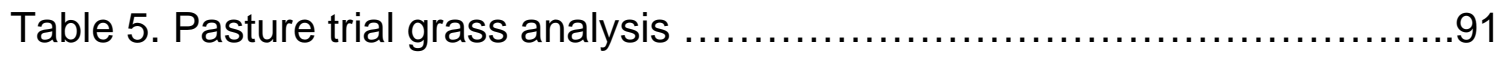

Table 6. Fescue, orchardgrass, and Native hay trials analysis $\ldots \ldots \ldots \ldots \ldots \ldots 1$

Table 7. Winter pasture grazing: Steer start and end weights and Average daily gain

Table 8. Weight gain and average daily gain of steers: effects due to forage type

Table 9. Level of soyhulls (kgs) fed to Native, OGHaylage, and OGHay treatments .93

Table 10.Beginning and end rump fat, rib fat, REA, and IMF 93

Table 11. INDF and ADL intake as a percentage of body weight 94 


\section{LIST OF NOMENCLATUREIABBREVIATIONS}

ADF- Acid Detergent Fiber

ADG- Average Daily Gain

ADL- Acid Detergent Lignin

AIA- Acid Insoluble Ash

ARS- Agricultural Research Service

BQA- Beef Quality Assurance

BW- Body Weight

CP- Crude Protein

CRD- Controlled Release Device

DDM- Digestible Dry Matter

DM- Dry Matter

FFA- Free Fatty Acids

HCW- Hot Carcass Weight

IMF- Intramuscular fat

INDF- Indigestible Neutral Detergent Fiber

IVDMD- In Vitro Dry Matter Disappearance

ME- Metabolizable Energy

NBQA-National Beef Quality Audit

NDF- Neutral Detergent Fiber

NE- Net Energy

RDP- Rumen Degradable Protein

REA- Rib eye area

USDA- United States Department of Agriculture

VDMI- Voluntary Dry Matter Intake

VFA- Volatile Fatty Acids 


\section{Prediction of Forage Intake and Production of Steers in a Winter Forage System}

\section{Introduction}

Historically, cattle were finished mainly on forage until the 1970's when the United States went through a period of surplus grain. Thus grain became a source of cheap animal feed (Turner and Raleigh, 1977). Recently, an interest in predominantly forage-finished beef has been re-emerging. The Appalachian region of the United States combines a favorable climate, sufficient rainfall, and adequate cow-calf numbers to create the opportunity to produce beef, which is profitable to the producers, palatable, available, and affordable to the consumer. Furthermore, due to an increase in consumer demand for "all natural" and "grassfed" products, there is an interest in developing systems to produce these value added entities, especially in this region. In order for these systems to develop and remain viable, high quality forages must be supplied on a year round basis. Rising grain prices have also lead many producers to consider finishing cattle utilizing more forage and less grain.

The basis of forage production systems varies in different parts of the United States due to differences in native and naturalized grass species. Beef production systems, mainly cow-calf production, in the Appalachian region have historically been based primarily on naturalized forages (Poa pratensis L., Kentucky bluegrass; Dactylis glomerata L., orchardgrass; Festuca arundinacea Shreb., tall fescue; and Trifolium pratense L. and Trifolium repens L., red and white clover) with little grain. One major problem in the development of these systems is that there has been little work done evaluating the aforementioned 
forages as grazing crops through the winter period and for finishing ruminants (Barnes et al., 2003).

The productivity of ruminants depends on their ability to consume and extract usable energy from available feed (Fisher, 2002). One common factor limiting animal performance, especially through the winter, is dry matter intake. Furthermore, forages often have a low energy density compared to grain crops. Thus, animals may not be physically capable of consuming enough forage for high rates of gain. One of the little understood areas is determining the mechanisms that control intake in ruminants. Understanding all the factors affecting forage intake is not an easy task. Despite the many decades of intensive study, there is still no consensus on how intake is controlled, nor is there agreement about the way animals determine which foods to eat (Forbes and Provenza, 2000). It has been postulated that forage intake is the result of many interacting factors, including physical and chemical properties of the plant (fiber and lignin content), long (social interactions, daily intake over a period of time) and short-term factors (events within the day that affect the frequency, extent, and pattern of an animal's needs), and physical limitations of the animal itself.

Currently there are no means to accurately measure forage intake of a grazing animal. Nonetheless, there are several chemically defined fractions within the plant cell wall, including indigestible neutral detergent fiber (INDF), acid insoluble ash (AIA) and long chain alkanes, as well as exogenous entities that 
may be added to the feed (i.e. chromic oxide and ytterbium chloride) to aid in the determination of grazing animals intake.

The overall objective of this thesis is two-fold. First, evaluate variability in the consumption of intake markers commonly used to predict forage intake, as affected by grass species and hay processing treatment in a controlled environment and in the grazing situation; second, investigate the performance of steers in four winter forage feeding systems. These objectives will be assessed through a series of two experiments. 


\section{Review of Literature}

\section{General}

\section{Historical Production of Cattle}

During early United States history, cattle were finished primarily on forages. Due to fluctuations in grain prices, and a desire to finish cattle more quickly with less variability in quality, producers began to increase the amount of grain included in cattle diets. One downfall of increasing grain in a ration is the increase in production costs. Grain surpluses are diminishing, and the United States may be faced with producing beef with less concentrates. Because of this, in recent years, producers have once again begun to look to alternative methods for finishing beef. One of the most prevalent methods being revisited is the use of rangeland and pasture.

In 2001, 1,841 million tons of harvested grains in the United States fell 54 million tons short of the projected consumer use (Brown, 2001). World grain shortages in the 1970's caused an increase in demand for corn and sorghum, the United States' principle livestock feeds (Hodgson, 1977). Livestock producers are also being encouraged to develop more sustainable production practices, such as forage production, since only a small percentage of the earth's land surface is suitable for sustained grain production (Hoveland, 1986). Population Action International reported that the amount of arable land per capita decreased from 0.44 to 0.27 hectares, respectively from 1960 to 1999 (Engelman and LeRoy, 1995). Increasing concern for consumer health and production 
sustainability has led people to evaluate management methods and systems that fully utilize roughages and minimize grain for a large part of the feeding program.

\section{Production of Cattle Today}

In more recent years it has been a common belief that feeding high concentrate rations was the only way of producing consumer acceptable beef. Typical quality grades of pasture-finished animals fall in the Standard and Select ranges, which some consumers may find unacceptable. However, research has shown that pasture-finished animals can attain an acceptable quality grade of at least low Choice with little additional input. Agriculture Research Service (ARS) scientists from the Grazing Lands Research Laboratory at El Reno, Oklahoma reported that adding more forage and limiting concentrate still produced high quality beef compared to animals finished on high concentrate diets. Philips et al. (2002) reported quality and yield grades of Standard+ and 2.55 respectively, from stocker calves finished on grass. This compared with low Select and 2.86 quality and yield grades from animals finished on a conventional, totally confined feeding system (yield grades were based on a scale of 1 to 5). In other research, by Phillips et al. (2002) forage finished animals, given limited concentrate, yielded quality scores ranging from high Standard to low Choice. In the 2000 National Beef Quality Audit (NBQA), averages for hot carcass weight (HCW), fat thickness, quality grade, and yield grade were $356.9 \mathrm{~kg}, 1.2 \mathrm{~cm}$, select, and 3.0 respectively (McKenna et al., 2002). Results of Phillips et al (2002) were similar to or slightly less than the national average. With the increasing numbers of forage-finished cattle, the re-introduction of the backgrounding phase will be 
necessary. Backgrounding is a management system where recently weaned calves or yearlings are grazed or fed a high fiber ration for a period of time before being finished. Backgrounding is used to control weight gain so cattle gain adequate muscle and bone before laying down fat covering and marbling (House, 2003). This may be necessary in forage-finished animals in order to ensure they are at the physiological stage to be finished.

Ruminant animals can be raised on low forage diets, but there are many reasons why high levels of forage should be included in the diet. Ruminal function and animal health are best and production costs are lower for forages compared to grain. Perennial forage crops are more "environmentally friendly" and can be grown with more sustainablity because they provide protection against soil erosion, and reduce water pollution (Jung and Allen, 1995). Because of the low density of cattle in pasture conditions compared to feedlots, in many situations grazing does not contribute to water and air pollution. Less confined conditions provide drier, healthier feeding areas and eliminate the need for manure removal, saving veterinary costs and labor (Turner and Raleigh, 1977). In some areas, regulations require producers to capture, store, and dispose of all animal waste generated. When cattle are in a pasture situation, manure is distributed over the pasture where it is incorporated into the soil and used as fertilizer. Range or pasture feeding also requires less expense in the form of permanent feed bunks and handling equipment. Handling expenses may also be reduced because cattle can remain at the same location (Turner and Raleigh, 1977). 
Typically, increasing the use of forages in a ration lengthens the time required to reach a given weight and quality grade. In the United States, grain feeding is usually maximized and finish time is minimized to reduce overhead cost (Fontenot et al., 1985). If all-forage programs are to succeed, the same level of nutrients must be provided to the animals from forages, range, and pasture that would be provided by grain concentrate feeding. This possibility is highly unlikely, especially in select times of the year, when forage quality Is low, as it is during the winter feeding period. To be profitable, these animals need to produce rapid and efficient gains. Thus, animals would require more forage, forage of higher quality, and better utilization of the forage consumed. All of these factors mean greater outputs of digestible energy per acre that can be efficiently used by the animal, whether in grazing systems or in systems involving harvested forages (Hodgson, 1977). Overall, this means better forage and pasture management on the part of the producer.

The hills of the eastern United States contain one of the largest forage resources in the United States, the Appalachian mountain range. Pastures in the Appalachian Highlands are generally located on steep rough terrain in land classes VI and VII. In these pastures, predominant forages are naturalized coolseason grasses and legumes. Beef production is primarily a cow-calf enterprise, and calves are weaned and sold from late summer to early fall. To improve profitability, increasing numbers of calves are now retained in stocker systems after weaning (Allen et al., 1992, 2000). Developing a forage system for winterfeeding and for finishing steers will enable producers to retain their animals and 
increase income to the local economy. Fall-weaned calves can make efficient use of forage for growth during the winter and early spring, but few forage systems for stocker calves have been tested (Allen et al., 1992, 2000). Year round grazing systems are possible in some parts of the United States, especially in the southeast region. Climate and soils in the southeastern region are well suited for forage production (Allen et al., 2000). Limited research on year round grazing systems offers some insight into the development of high forage stocker and finishing systems.

Beef production systems in the Appalachian regions utilize naturalized grasslands, mainly comprised of Kentucky bluegrass, orchardgrass, and tall fescue, with some white and red clover (D'Souza et al., 1990). These species are high quality, especially in early spring. Major research efforts in this region have been directed towards improving soil fertility and botanical composition of pastures, with little emphasis on grazing management. One problem is that most grazing experiments were conducted under continuous stocking with relatively low numbers of animals (Bryan et al., 1987). In order for wintering programs to be successful, it may be necessary to utilize rotational or strip grazing in order to reduce spoilage and trampling of forages by the animals. Also, for winter feeding programs to be applicable to the Appalachian region, it is necessary to test grazing systems using larger numbers of animals.

The greatest expense a stocker cattle producer incurs is in the feeding of conserved forage during the wintering phase. One possibility to reduce the need for harvested forage and associated costs, is extended grazing on permanent 
pastures and aftermath hayfields (D'Souza et al., 1990). Forage is allowed to accumulate in late summer for use in fall and winter (Hall and Jung, 1993). This practice is called stockpiling. Despite the advantages of stockpiling, there is one major downfall; these grasses lose quality during the winter period and the performance of stocker cattle may be reduced during late fall and winter (Baker et al., 1988; Balasko, 1977). Furthermore, all cool season forages are not the same in their growth and quality attributes and may also vary in suitability for stockpiling.

\section{Cool Season Grasses in the Appalachian Region}

Cool-season grasses are used for pasture and hay in the spring, summer, and fall (Barnes et al., 2003). These grasses have a vernalization or day length requirement for flowering. Vernalization triggers the plant to go from a vegetative to reproductive state. This change results in less vegetative growth, which means a reduction in the high quality portions of the plant. The vernalization requirement is species specific, but is generally four to six weeks of temperatures less than six degrees Celsius during winter while growth is very slow or arrested (Fahey et al., 1994). The period of vegetative growth, prior to the reproductive state is beneficial to plant quality because the plant is producing higher quality leaf material rather than fibrous stem material, thus providing a higher quality and more digestible diet for the animal. Cool-season grasses differ in palatability and physical texture, both factors influencing intake. Of the cool-season forages mentioned thus far, a description of the attributes of each are to follow. General 
characteristics regarding growth and use, as well as quality issues will be discussed for each species. One of the major problems that will be discussed is the possibility of the presence of alkaloids, primarily in tall fescue, reed canarygrass, and possibly ryegrass. Alkaloids in tall fescue and reed canarygrass are the result of endophyte infection. This endophyte produces alkaloids causing reduced palatability in infected plants, as well as problems associated with animal performance.

\section{Kentucky Bluegrass}

\section{General Characteristics}

Kentucky bluegrass is well adapted to the Appalachian Region and is an important high quality forage in the north central and northeastern regions of the United States. Kentucky bluegrass, a perennial grass, is often used as pasture, and becomes dormant during midsummer when temperatures are high (Smith, 1975; Allen et al., 2000). During this time growth declines rapidly due to the plants' low tolerance of heat (Allen et al., 2000). Kentucky bluegrass continues to grow into October and November but production is low (Bryan and Mill, 1988). Kentucky bluegrass is not widely used as a hay crop, but it is an important grass in permanent pastures because of its persistence (Martin and Leonard, 1967). It is very tolerant of close continuous grazing due to its extensive system of rhizomes and ability to maintain leaf area near the soil surface (Barnes et al., 2003). In order to attain high levels of forage production, an ample supply of nitrogen and phosphorus are essential (Martin and Leonard, 1967). Bluegrass 
begins its growth in early spring thus providing succulent forage for early grazing (Martin and Leonard, 1967).

\section{Potential for Stockpiling}

When mature, Kentucky bluegrass is lower in protein and digestibility than young grass, but it can still provide acceptable medium quality forage. In an experiment conducted by Taylor and Templeton (1976) using stockpiled tall fescue and Kentucky bluegrass, it was found that Kentucky bluegrass consistently had higher crude protein values that tall fescue. Crude protein in the green component of Kentucky bluegrass ranged from 14.6 to $17.9 \%$, lowest being during December, and highest crude protein during October and March. Following stockpiling there was no reduction in forage regrowth the following spring. Conflicting data has shown that the potential for stockpiling Kentucky bluegrass may be limited because the practice may result in loss of forage the following year (Ohio State University Extension, 2005). This is most likely a result of animals grazing available forages too low and removing the reproductive buds.

\section{Ryegrasses}

\section{General Characteristics}

In the past, ryegrasses (Lolium spp.) have been the most widely grown cool-season annual grasses throughout the United States (Hall, 1992). Under optimun conditions, ryegrasses establish rapidly, are high yielding with a long growing season, and have high digestibility and nutrient content. They can be grazed or used as hay or silage. An advantage of the ryegrasses is that they have a high forage quality and, when alkaloid free, are more readily consumed 
by animals because of their soft textured leaves and fine stems compared to other species (Barnes et al., 2003). However, some varieties contain alkaloids that may depress animal performance, and, in the eastern half of the United States, plants typically survive for about one year (Barnes et al., 2003; Martin and Leonard, 1967).

\section{Potential for Stockpiling}

During less than optimum periods, such as drought or periods of extended high or low temperatures, growth is greatly depressed (Hall, 1992; Barnes et al., 2003). Allen et al. (2000) reported that rye was available from autumn into late spring for grazing. Because growth becomes depressed during extended period of low temperatures, perennial ryegrass is less winter-hardy than other cool season grasses (Barnes et al., 2003; Hall, 1992). Because of decreased tolerance to cold weather, ryegrasses are less than ideal for stockpiling.

\section{Types of Ryegrasses}

Two types of ryegrass predominant in the Appalachian region: Lolium multiflorum Lam. (Italian ryegrass) and L. perenne L (Perennial ryegrass). Perennial ryegrass is typically found in the southeast and northwest regions of the United States. This species is typically highly palatable and digestible (Hannaway et al., 1999). Perennial ryegrass is less winter-hardy than orchardgrass and tall fescue and less drought tolerant than smooth bromegrass.

\section{Orchardgrass}

\section{General Characteristics}

Orchardgrass is a perennial, tall growing grass. It begins growth in early spring and has no rhizomes or stolons. It is a bunch type grass and when not 
grazed properly or mowed, large tussocks may form (Myers, 1962).

Orchardgrass is more tolerant of shade, drought, and heat than timothy, perennial ryegrass, or Kentucky bluegrass (Martin and Leonard, 1967; Hall, 1994a; Myers, 1962). Orchardgrass grows more rapidly in cool weather compared to the aforementioned species (Myers, 1962). Maturity is one of the most important factors influencing the nutrient composition of orchardgrass. In spring and fall, plants accumulate high levels of soluble carbohydrates (Hannaway et al., 2004). When cut at a grazing height of 4 inches, there is a low leaf to stem ratio, relatively high protein, and a high soluble carbohydrate concentration (Rayburn, 1992). When growth becomes vegetative in the fall, after reproductive buds have been removed by animals grazing or mechanical harvesting, plants have a high leaf to stem ratio, high protein, and low soluble carbohydrate concentration. As plants mature following the vernalization period, and begin to undergo reproductive development, there is a rapid decline in protein and carotene along with a marked increase in crude fiber and lignin concentration (Myers, 1962). This decrease in carotene content may be beneficial to meat quality because carotenoids contribute to yellow fat often seen in forage finished animals. This grass becomes coarse and less palatable as it matures (Hall, 1994a; Smith, 1975; Myers, 1962). An advantage of this species is that it recovers rapidly after grazing or mowing and as a result will continue production throughout the grazing season. A problem is production suffers when temperatures exceed 30 degrees Celsius (Myers, 1962; Hannaway et al., 2004). 


\section{Potential for Stockpiling}

Orchardgrass may have potential as a forage to extending the grazing season. Orchardgrass has been shown to retain sufficient quality to sustain beef animals during late fall (Baker et al., 1988). Little is known about the potential of stockpiling orchardgrass for winter grazing (Allen et al., 1992). There is limited information on how well orchardgrass will withstand the cold winter temperatures in the Appalachain region. Limited research has shown orchardgrass stands to tolerate cold winters in areas where the average annual temperature does not fall below 1 degree Celsius (Hannaway et al., 2004). Orchardgrass has some potential for stockpiling, under the correct management. Hay should be harvested by mid-June. If orchardgrass fields are grazed, plants should not be grazed shorter than 2-3 inches. Orchardgrass stores energy in the lower part of the stem and roots, so removal of the lower part of the stem may result in plant death (Ohio State University Extension, 2005).

\section{Tall Fescue}

\section{General Characteristics}

Tall fescue grows well under a wide range of soil and climatic conditions, including semi-wet, and both acidic and alkaline soils (Bagley et al., 1983; Martin and Leonard, 1967). In the upper south, tall fescue forms the basis for many forage-livestock systems, and endophyte-free pastures provide a low-cost feed for beef stocker production (Allen et al., 2000; Hoveland 1986). Tall fescue is more tolerant of drought, resists frost better than other forage species, and will maintain itself under rather limited fertility conditions (Hall, 1994d; Barnes et al., 2003). The species is also more tolerant of continuous stocking, and can 
withstand closer grazing than other grasses (Barnes et al., 2003; Hall and Jung, 1993). Close grazing along with nitrogen fertilization may maintain the plant in a succulent, more palatable condition (Martin and Leonard, 1967). Tall fescue is a high quality grass that is similar in forage quality to orchardgrass or bromegrass (Baker et al, 1988; Hancock et al., 1987). Baker et al (1988) found that tall fescue's fall quality (as measured by In vitro dry matter digestibility, crude protein (CP), NDF, and ADF concentrations) was superior to orchardgrass.

\section{Endophyte Infected Tall Fescue}

Despite the attributes of tall fescue, there are some concerns with its use. The primary problem with tall fescue is that some varieties are not very palatable. Animals will readily graze fescue during April, May, and early June, and again in the fall, but show reluctance to graze it during July and August (Hall, 1994d). Reduced palatability is often associated with the fescue plant being infected with an endophytic fungus. This fungus (Neotyphodium coenophialum) produces ergot alkaloids resulting in adverse effects on the health and performance of animals grazing the plants (Allen et al., 1996; Fahey et al., 1994; Hall, 1994d). Reduced palatability and animal performance are the result of alkaloids interacting and interfering with prolactin secretion, body temperature regulation, and feed intake, and the effects are exacerbated by high temperatures (Paterson et al., 1995; Bagley et al., 1983). Including a legume with endophyte infected fescue can improve animal performance while reducing the effects of toxicity (Allen et al., 1996; Hall 1994d; Hall and Jung, 1993). Allen et al (1996) fed 
fescue hay or silage and compared it to grazing stockpiled fescue during the stocker phase.

\section{Potential for Stockpiling}

Unlike the other cool season grasses mentioned thus far, substantial work has been done with stockpiling tall fescue, especially in the southeastern region of the United States. Tall fescue is well suited for stockpiling from late summer to early autumn (Barnes et al., 2003; Allen et al., 2000). Stockpiling tall fescue in late summer and early autumn provides high quality forage for grazing beginning around November, but declines throughout the winter period in the Southeast region of the United States (Allen et al., 2000). Tall fescue has the ability to provide more grazing days in fall and winter than other fall growing cool-season species (Balasko, 1977; Hall, 1994d). Rayburn (2001) states that the forage quality of stockpiled fescue may not be optimal for growing animals and a energy or protein supplement may be necessary. Stockpiled fescue may extend the grazing season, while, at the same time, minimize hay-feeding needs, compared to other winter forage systems (Allen et al., 2000). Bagley et al (1983) reported that stockpiled tall fescue deteriorated due to winter burn, and consequently had poor forage quality and low voluntary intake by grazing ruminants during the month of February. Animal performance may be limited by nutrient losses caused by weathering (Hitz and Russell, 1998). Research in Virginia showed that proper management of tall fescue for stockpiling includes the application of 70-90 $\mathrm{kg}$ of nitrogen per hectare in early August to ensure optimum forage yield (Allen et al., 1992). The amount of nitrogen fertilizer required for stockpiling tall fescue 
makes the inclusion of a legume more difficult and stockpiling fescue for autumn grazing prevents its use in the late summer and early autumn (Allen et al., 2000). Although quality declines over the winter, stocker cattle can make good use of this forage with limited supplemental hay until forages begin to grow the following spring (Allen et al., 2000).

\section{Smooth Bromegrass}

\section{General Characteristics}

Smooth bromegrass (Bromus inermis L.) is a leafy, sod forming, perennial grass that can be used for hay or early spring pasture (Hall, 1994c). It is typically deep rooted with numerous underground rhizomes, and therefore is well suited for steep slopes (Hall, 1994c; Martin and Leonard, 1967). Bromegrass is capable of surviving drought as well as extremes in temperature, but makes its best growth on moist, well-drained clay to silt loam soils, but is somewhat tolerant of acidic soils (Hall, 1994c; Martin and Leonard, 1967; Smith, 1975). Smooth bromegrass typically has less summer growth than orchardgrass (Hall, 1994c). When harvesting smooth bromegrass, the most important factor to consider is growth stage (Hall, 1994c). During the tillering stage of growth light grazing is necessary in order to allow ample growth of the plants (Hall, 1994c; Smith, 1975; Hitz and Russell, 1998). Forage quality of smooth bromegrass is higher than most other cool season grasses such as orchardgrass or tall fescue (Bassford, 2000). During periods of rapid growth, smooth bromegrass is high in crude protein (12 to greater than 20\%), especially on fertile soils (Newell and Anderson, 1962). There are several disadvantages of smooth bromegrass including the fact that plants are adversely affected by early harvesting of the spring growth and 
delaying harvest beyond early bloom will cause large reduction in forage digestibility and protein content and low productivity when grown alone and without nitrogen fertilizer (Smith, 1975; Hall 1994c). Smooth bromegrass must be managed with some care.

\section{Potential for Stockpiling}

Summer pasturing may result in overgrazing and close grazing during the fall and may cause reduced growth next spring (Bassford, 2000; Barnhart, 1998). In the Appalachian area, it may be difficult to grow bromegrass, as it is not well adapted to the acidic soils of the east (Barnes et al., 2003).

Timothy

\section{General Characteristics}

Timothy (Phleum pratense L.), one of the most important cultivated grasses in the United States, is a perennial, bunch type, shallow rooted grass (Hall, 1994e; Martin and Leonard, 1967). Due to its shallow root system, this grass is unsuited to droughty soils. Timothy is tolerant of acidic to moderately alkaline soil conditions. Timothy stores energy for regrowth and tillering in haplocorms at the stem base (Hall, 1994e). Timothy is better for hay than other species and the cool fall weather is more suitable for growth. When grown in mixtures, the first growth is frequently harvested for hay, and aftergrowth is used as pasture (Hanson and Evans, 1962). Timothy may be easily weakened by frequent cutting and heavy grazing (Hall, 1994e; Smith, 1975). Once mature, timothy retains its palatability and feed value better than other cool season grasses, and, when mixed with clover, can provide an excellent forage for ruminants (Martin and Leonard, 1967). 


\section{Potential for Stockpiling}

There is evidence to show that timothy has some potential for stockpiling, but it is better adapted to late fall grazing rather than winter grazing. Conflicting data presented by Baron et al. (2004), from Canada, said that timothy provided greatest stockpiled yields in years with above average rainfalls compared to Kentucky bluegrass.

\section{Reed Canarygrass}

\section{General Characteristics}

Reed canarygrass (Phalaris arundinacea L.) is a tall leafy high yielding perennial grass, which under certain conditions is considered winter hardy (Hall, 1994b). Reed canarygrass is more resistant to foliar diseases than other coolseason grasses. It is tolerant to flooding and standing water (Hall, 1994b). Reed canarygrass is used primarily for pasture during dry summer periods as well as throughout the growing season (Hall 1994b; Smith, 1975). For best quality plants should not be permitted to make excessive growth or go to full maturity (Heath and Hughes, 1962). Increases in the proportion of stem relative to the leaf is the primary cause of decline in quality (Hall, 1994b). A decline in palatability accompanies this decrease in quality (Smith, 1975). 


\section{Potential for Stockpiling}

Reed canarygrass is sometimes considered more winter hardy than tall fescue, but leaves are very frost sensitive, turning brown very quickly after early frosts and therefore not retaining quality into late fall and early winter (Hall, 1994c).

\section{Palatability and Presence of Alkaloids}

Reed canarygrass is equal in quality to other cool-season grasses at the same stage of maturity, but when given a choice, animals will choose something else due to plants' coarseness. This is accentuated when it is a high alkaloid variety, or the plants are allowed to become mature before grazing (Hall, 1994b; Nelson and Moser, 1994).

\section{Grazing Systems}

A grazing system is an integration of soil, plant, animal, environmental, and management factors that function as a whole with the objective of matching the feed requirements of the livestock to the production and quality potential of the forages (Allen et al., 2000; Barnes et al., 2003). Maximum economic return from forages in beef production systems results from the highest possible conversion of available digestible energy to meat (Hodgson, 1977). In grazing systems at least two approaches to improving economic gains are possible. The first is to minimize trampling and fouling of forage. These losses can be very substantial on highly productive pastures especially with heavy stocking rates. The second is to portion herbage on the basis of quality according to the nutritional needs of animals for various physiological functions (Hodgson, 1977). 
This becomes very important in winter grazing systems since forage growth is minimal. As pointed out by Kaiser and Faulkner (1991), the perfect pasture system must supply sufficient high quality pasturage during the grazing season to maximize genetic potential of the grazing animals or sufficient pasturage to meet the goals of the production system.

Many successful systems of wintering beef cattle on minimum barn stored hay have been developed using tall fescue as the principle forage (Balasko, 1977). However, tall fescue is not usually the principle forage available on farms in the upper Appalachian region. Many producers rely on naturalized pastures consisting mainly of Kentucky bluegrass and white clover. Secondly, many of these systems are designed to maintain a mature beef cow and not to winter calves destined to be forage finished the following grazing season. Thus, other forage alternatives need to be explored

\section{Extending the grazing season}

The winter period in northern Appalachia can last up to six months, and usually requires the feeding of conserved forages to the beef herd (Prigge et al., 1999). This conservation has been traditionally achieved through harvested feed. Alternatively, extending the grazing season into winter reduces feed costs and increases profitability (Hitz and Russell, 1998; Lewis et al., 1990; Prigge et al., 1999). Several strategies can be employed to supply forage into the fall or early winter and effectively extend the grazing season 60 to 90 days (Hall and Jung, 1993). These strategies fall into two major groups. The first is stockpiling. 
Stockpiling is the practice of conserving standing forages in late summer for use in early fall and winter. The second strategy is using forage crops which continue to grow in fall and early winter. The problem with this second method is that there in inadequate research to determine if any species are adapted to this method.

\section{Stockpiling}

Most forage species reduce their growth in the fall as a result of shorter day lengths and cooler temperatures, as well as lose their leaves and thus their quality after the first killing frost (Hall and Jung, 1993). Cool-season forages that grow well in the fall include tall fescue, prairie grass, perennial ryegrass, and some brassica crops (Hall and Jung, 1993). Stockpiling tall fescue for winter grazing has shown to be superior to orchardgrass and bluegrass in terms of forage quality and total dry matter production (Bagley et al., 1983).

One way of managing tall fescue with the goal of stockpiling is to apply nitrogen in spring, making hay from first growth and then allowing regrowth to accumulate until late fall and winter. At this time, previously harvested hay and regrowth may be grazed (Balasko, 1977). Quality of regrowth forage in winter may be increased by taking two summer cuttings instead of only one (Balasko, 1977). Allen et al (2000) found that at the beginning of grazing stockpiled tall fescue, more forage mass was available for grazing compared to autumn growth of alfalfa-orchardgrass that followed the last hay cut or to rye planted in September. Rye provided about 14 days more grazing than alfalfa-orchardgrass, but alfalfa-orchardgrass was more flexible within the system because it was also 
grazed, if needed, during the summer. There are several disadvantages of these systems tested by Allen et al. (2000). First, orchardgrass-alfalfa fields must be reestablished; whereas; tall fescue stands can be maintained indefinitely. The reason for this is because alfalfa stands deteriorated by the end of the grazing experiment. Another problem with systems tested by Allen et al. (2000) was that growth of bluegrass-white clover decreased during summer stress resulted in lower forage mass available for grazing animals due to stocking rate and animal demands for forage.

\section{Use of Legume Mixtures for Stockpiling}

Research conducted in Virginia by Allen et al (1992) examined all forage systems for stocker cattle. They determined productivity and longevity of fescue grown with either alfalfa or red clover, compared to nitrogen-fertilized fescue, managed as stockpiled forage. Tall fescue was harvested for hay in early August, $90 \mathrm{~kg}$ of nitrogen per hectare were applied by mid August, and herbage allowed to accumulate until grazing began in late October. Fields containing alfalfa or red clover were stockpiled in the same manner, but without the application of nitrogen fertilizer. If forage availability became limited, calves were supplemented with hay, previously cut from that field. Cattle grazing stockpiled fescue-legume required more hay and more days of hay feeding than animals grazing nitrogen fertilized stockpiled tall fescue. The use of stockpiled forages reduced the need for stored forage, but inclusion of legumes did not provide as much grazed forage as did the use of nitrogen fertilizer. Cattle consumed the 
maximum amount of stored feed during March. Allen et al (1992) showed that allocating 0.27 hectares of stockpiled tall fescue per stocker animal provided grazing from early November until late March, with supplemental hay feeding required for only 33 days while supporting daily gains of $0.34 \mathrm{~kg}$.

Warm season grasses also have potential to be stockpiled for winter grazing, but their quality is often lower than cool-season grasses. In addition, they become dormant during autumn and therefore do not accumulate nonstructural carbohydrates (Barnes et al., 2003).

\section{Forage Systems and Animal Performance}

There is limited information regarding effects of all forage systems on growth performance and carcass attributes of steers in the Appalachian region. However, all forage systems have been investigated in other regions of the United States

\section{Forage Diets with Supplementation}

Coombs et al (1990) looked at year round production systems in the southern United States and compared cattle fed high-energy corn silage in a dry lot to forage-finished cattle. The forage-finished cattle grazed an array of cool and warm season forages, and were fed some supplemental grain, depending on season and location. The corn silage fed animals were heavier at slaughter, and slaughter weight of the forage-grazed cattle was more variable, depending on season and forage availability. It was concluded that more intensive management and cost effective techniques were needed to finish cattle on forages throughout the year compared to cattle finished on silage. Despite this, potential profit was greater for forage-finished livestock at select times of the 
year. In addition to greater variability in animal performance, another problem identified by Allen et al (1996), associated with "grass fed" cattle, is yellowness of fat. This characteristic may decrease consumer acceptability. Yellow fat is the result of carotenoids in grasses being deposited in the fatty tissues of the body, and may be influenced by breed. Diet prior to finishing may also effect carcass quality but little is known about the influence of previous forage diet on growth performance of cattle during the finishing phase. Effects of forage species on performance and carcass characteristics in a forage-based system are not well understood.

\section{All Forage Diets}

Sainz and Vernazza-Paganini (2004) conducted an experiment in California, repeated over three consecutive years, to study the effects of various grazing and feeding periods on steer performance and carcass traits. Weaned steers were shipped to either a feedlot (calf-fed), grazed on irrigated pasture until September, then sent to a feedlot (short yearlings), or grazed on irrigated pasture until September, moved to native range until May-June, and finally sent to the feedlot (long yearlings). Pastures consisted of annual and perennial ryegrass, orchardgrass, and a mixture of clovers. Researchers found that there was no difference in feedlot ADG, but tended to increase with shorter backgrounding times. Because all animals were slaughtered at a group average of 11 to $12 \mathrm{~mm}$ of backfat, there were no differences in kidney, pelvic, and heart fat or subcutaneous fat. There was, however, an increase in carcass fat percentage in short yearlings compared to long yearlings. A possible explanation for this is that 
exposing the animals to a feed restriction resulted in compensatory growth during the ad libitum feeding phase. Another possible explanation is that short yearlings had access to higher quality forages, earlier in the growth curve, allowing them to grow more quickly and deposit fat at an earlier age than long yearlings. Overall, the long yearlings tended to be leaner. Compared to the other two groups, the long yearlings had less intramuscular fat. This response may have been due to insufficient time on feed (i.e. energy availability) to achieve the same degree of marbling as calves and short yearlings. This research confirms the conclusion that animals backgrounded on forage have elevated mature sizes and therefore must reach heavier weights in order to achieve acceptable market finish. Because grazing animals gained weight without increasing backfat, prolonged backgrounding may decrease quality grade by either impairing the ability of the animals to deposit intramuscular fat, or by decreasing the time during which dietary energy supply is adequate for intramuscular fat deposition to occur (Sainz and Vernazza-Paganini, 2004). However, this decrease in intramusular fat may only pose a problem if grass-fed cattle are marketed by traditional means.

Allen et at (1996) conducted a seven-year experiment, in part, to look at the influence of forage system at the stocker phase on performance and carcass characteristics. Stockers were randomly allotted to one of the six all-forage systems including; stockpiled nitrogen fertilized tall fescue; tall fescue-red clover; or tall fescue-alfalfa; or were barn-fed tall fescue hay; alfalfa-orchardgrass hay; or tall fescue silage from late October to early April. At the end of the stocker phase, cattle were allotted to one of three forage systems for the finishing phase. 
These systems were nitrogen fertilized tall fescue; bluegrass-white clover sequence grazed with tall fescue-red clover; or bluegrass- white clover sequence grazed with alfalfa-orchadrgrass. Heifers were fed corn grain daily at $1 \%$ of their body weight from July until they were slaughtered in October. Remaining steers grazed the same paddocks as grain-fed animals, but received no grain. The non-grain fed steers were fed corn silage from October until the time of slaughter in January. Steers, grazed on tall fescue prior to finishing had less longissimus muscle area, $\mathrm{KPH}$, and fat thickness, and lower yield grades, marbling scores, and quality grades than steers from grass legume systems. Most of the differences seemed to occur in steers slaughtered after being in the feedlot. Improvement in quality grades was seen in all cattle grazing alfalfa-orchardgrass. An increase in quality grade was seen in animals finished on corn silage following a grazing period (Allen et al., 1996). Improved performance of cattle finished on corn silage compared with cattle finished on grazed forages with grain-on-grass is consistent with results from Coombs et al (1990), as discussed previously. In this study, researchers observed little effect of forage system on fat color. It was noted, however, that season long grazing of fescue did result in more yellow fat compared to wintering on fescue and subsequently grazing mixed forages (Allen et al., 1996). Stocker systems containing more alfalfa during the finishing phase resulted in higher quality grades. During a feedlotfinishing period, steers had more backfat and rib eye area when they came from an alfalfa-orchardgrass stocker system. Wintering cattle on fescue hay or fescue silage resulted in lighter cattle at the end of the stocker phase, and animals did 
not experience sufficient compensatory gains to overcome this (Allen et al., 1996).

\section{Temperature Effects on Animal Performance}

In addition to forage quality and type, season and temperature can also affect an animal's performance. Cattle show marked decreases in performance under extreme cold stress. In animals fully acclimated to cold temperatures, heat production at maintenance may be increased $30-40 \%$. In addition, metabolic rate of feedlot cattle increases approximately $2 \mathrm{kcal} / \mathrm{kg}$ of $\mathrm{BW}^{75}$ for each degree that environmental temperature is below the lower critical temperature (Delfino and Mathison, 1991). Cold environmental conditions may also cause an increased rate of digesta passage, which leads to reduced digestive efficiency (Delfino and Mathison, 1991). This increased passage rate, coupled with animals increased energy demands, can become a problem with winter grazing animals on lower quality forages and it may be necessary to provide supplementation. Previous research has suggested a considerable reduction in growth efficiency during the winter (Delfino and Mathison, 1991).

\section{Forage quality}

Diet composition influences health and productivity of grazing animals (Kelman et al., 2003). Balancing rations for grazing cattle in order to optimize productivity is difficult because of the lack of data for nutrient content, lack of descriptive changes in the sward over the season, and the inability to accurately estimate intake when grazing (Martz et al., 1999). Some constituents of plants, such as tannins and lignins, have inhibitory effects on grazing animals. Tannins 
in low concentrations help to reduce the incidence of bloat as well as increase nitrogen utilization, but high concentrations reduce the rate of digestion and forage intake (Kelman et al., 2003). Lignification is considered to be the primary impediment to forage digestibility. Jung and Allen (1995) state that there is a negative correlation between lignin concentration and DM and Neutral Detergent Fiber (NDF) digestibility. Because lignin is the major factor providing structural strength, it becomes the greatest limitation to breakdown of stems in the rumen (Nelson and Moser, 1994).

Forage is not a homogenous diet, instead, it is either a single plant species, or a mixture of plants comprised of leaf blades, leaf sheaths and stems, and reproductive structures (Fahey et al., 1994). Ruminants are selective grazers, and nutrient content of the pasture consumed is usually different from the nutrient content of the pasture offered (Martz et al., 1999). Morphological development of the plant and environmental conditions affect the amount and quality of each component (Nelson and Moser, 1994).

One of the best methods for improving efficiency of forage utilization is to increase forage quality. Forage quality is defined as the "sum total of the plant constituents, both chemical and physical, that influence an animal's use of the feed and make it valuable to an animal as a source of nutrients" (Cherney, 1994; Barnes et al., 2003). Forage quality can be measured by consumption and digestibility but may be described by animal performance (Vicini et al., 1982; Felton and Kerley, 2003). Overall feeding value of a forage is influenced by the form fed, forage palatability, and quality of other feeds in the ration (Cherney, 
1994). The option livestock have to select among the components will determine diet quality (Fahey et al., 1994). Martz et al (1999) found that similar animals on pasture selected plants that contained similar amounts of NDF, acid detergent fiber (ADF), crude protein, digestible dry matter (DDM), and net energy (NE).

Other factors that affect forage quality are; forage species, stage of maturity, harvesting conditions and climatic factors, such as solar radiation (Barnes et al., 2003; Fahey et al., 1994; Martz et al., 1999; Nelson and Moser, 1994). Secondary influences on forage quality include temperature, soil moisture during growth, soil fertility, and cultivar (Barnes et al., 2003; Nelson and Moser, 1994). All of these factors affect the anatomy and morphology of the plant, such as growth process, tillering and branching, internode elongation, leaf expansion, and flowering, thus affecting the quality (Barnes et al., 2003).

Temperature has a large impact on cell wall constituents of the plant. At lower temperatures, cell wall materials are deposited and are less lignified, resulting in higher digestibility (Fahey et al., 1994). Thus, forages grown for stockpiling should have higher digestibility than those grown at other times of the year. Furthermore, water stress, with minimal heat stress, often improves forage quality. This is due to an increased leaf: stem ratio and higher digestibility in both leaf and stem fractions (Fahey et al., 1994).

Plant maturity is also a major factor in forage quality. A decline in quality with age results, primarily, from a decrease in leaf: stem ratio and a decline in quality of the stem component (Nelson and Moser, 1994). In cool-season grasses, lignin and hemicellulose-lignin concentrations increase with maturity 
more in stems than leaves. Due to the proportion of leaf material present, leaf quality affects overall forage quality, largely because leaves are the highest quality part of the forage plant (Nelson and Moser, 1994). The leaf blade fractions of legumes generally decline very little in digestibility and crude protein with maturity. Immature stems are high in quality, but their quality decreases faster than leaves, especially as plants approach maturity (Nelson and Moser, 1994). Thus, one can see that there are many factors that have an impact on forage quality.

\section{Digestibility of Forages}

Digestibility may be expressed as the percentage of dry matter or the percentage of an individual constituent that is digested as material passes through the animals' digestive tract. Chemical composition determines the nutritive value of forages and that there is a negative association between digestibility and lignin or fiber content (Van Soest, 1965). The dry matter portion of a plant can be divided into a fibrous part (cell wall constituents) and a soluble part (cell contents; Figure 1). The detergent soluble portion of the plant is nearly completely digestible and not affected by lignification in any way, while the digestibility of the insoluble part is partial and varies according to the lignin content of the fiber fraction (Van Soest, 1965; 1967). As a plant ages, the amount of indigestible structural carbohydrate increases, making the entire plant less digestible (Nelson and Moser, 1994). Finishing beef cattle economically on forage will require forages with high dry matter digestibility and high intake potential in order to maximize daily intake of digestible energy and result in a satisfactory rate of gain (Hodgson, 1977). While fertilizers increase yield and, in 
some instances, protein content, dry matter digestibility usually is not increased significantly (Hodgson, 1977). Relatively small increases in dry matter digestibility usually result in major increases in animal performance and the payoff from cultivars with higher dry matter digestibility could be very large with respect to finishing cattle on forage (Hodgson, 1977). Effects of forage consumption and nutritive value may be characterized according to how chemical constituents affect intake, digestibility, and the relationship between intake and digestibility. Cool-season grasses typically have about $80 \%$ digestibility two to three weeks after growth begins (Barnes et al., 2003). One reason is coolseason grass forages accumulate higher levels of readily digestible nonstructural carbohydrates under favorable fall growth conditions. After this time, digestibility declines $0.3-0.5 \%$ each day harvesting is delayed. In general, cool-season grasses have about 13\% higher digestibility than warm-season grasses (Barnes et al., 2003).

Van Soest (1965) outlines three classifications for forage composition factors that affect nutritive value and digestibility of a forage. The three classifications are a) the factor affects intake but has no direct or reliable effect on digestibility; b) the factor promotes a positive relationship between intake and digestibility; and c) the factor promotes a negative relationship between intake and digestibility (Van Soest, 1965). An example of the first class is any toxic or inhibitory material or substance that impart taste, either objectionable or desirable, or may alter the metabolism of the animal. The second class includes factors associated with plant maturity, especially the fiber components. A forage 
that contains greater fiber mass and bulk, is more slowly digested than nonfibrous feeds. The effects of fine grinding and pelleting are closely related to this class. Since in these instances the volume and time of passage of the fibrous parts are reduced. The third class is illustrated by the fact that as fiber increases, digestibility decreases and the animal must consume more to meet its energy requirements (Van Soest, 1965).

\section{Control of Intake}

Intake is considered the most important component of performance in grazing animals (Lippke, 2002, Mertens, 1987; Illius et al., 2000). Productivity of ruminants depends on their ability to consume and extract usable energy from available feeds (Fisher, 2002). Many things, including animal and dietary characteristics, control intake. The most commonly accepted intake regulators are changes in glucose or other metabolites (chemostatic control), changes in body temperature (thermostatic control), and changes in body fat (lipostatic control; Mertens,1994). In addition, changes in amino acids (aminostatic control), the modulating effects of taste (palatability or gustatory control), habit, experience, social and emotional factors, and gastric distension (fill limitation) have also been proposed as factors altering intake (Mertens,1994).

When animals are fed low fiber, high-energy diets that are palatable and readily digested, intake is regulated to meet energy demands, and will be controlled by physiological energy demand of the animal, making control a function of animal characteristics (Mertens, 1994; 1987). If an animal is fed a high fiber, low energy diet, intake then becomes limited by the physical capacity 
of the animal, and becomes a function of dietary characteristics (Mertens, 1987; Journet and Remond, 1976). Animals have no mechanism for measuring energy directly, nor is caloric intake regulated as it in ingested. Instead, daily intake is adjusted indirectly to maintain an energy balance (Mertens, 1991). Level of energy intake influences body composition of the animal (Old and Garrett, 1987). If the energy density of a forage is changed, the animal will adjust its intake to balance the caloric input with its output (Fahey et al., 1994). This adjustment may be problematic during the winter-feeding period when forages are not as high quality as they are during the grazing period. This may result in energy intake that cannot meet the animal's potential demand, and the animal will then reduce performance or lose weight to accommodate the limits of the diet (Fahey et al., 1994). An example of the animal's adjustment in intake due to energy content of the diet and energy needs is in a cold environment. In this situation, the animal's energy demands increase, and the animal will attempt to match the increased energy required by increasing its intake (Fahey et al., 1994). This process presents a problem when cattle are consuming a forage-based diet. There are several factors, to be discussed later, that may limit the amount of forage an animal will consume. If animals are fed a low quality diet, there is the possibility they will not be able to meet their energy requirements. If energy concentration is too low and intake cannot be adjusted to accommodate a target level of production, the animal will reduce energy output by reducing productivity or increasing their use of energy reserves (Fahey et al., 1994). 
Gastrointestinal fill has been the subject of many studies as the main limitation of intake. Illius and Jessop (1996) posed the question "Why is voluntary intake so difficult to predict?" They answered; "Because it involves the neural integration of many signals and is subject to psychological factors." It is believed that there is no one single control of intake, but instead, factors and signals are additive. Researchers have identified many factors that correlate with intake, and they have suggested that many of these factors help regulate intake. Nonetheless, they have been unable to identify any single regulating factor. Several theories have been developed regarding forage intake. The "physical" theory is based on the observation that forage intake is often related to the rate or extent of digestion in the rumen. This theory is supported by the discovery of receptors in the rumen wall that are sensitive to stretch and touch. Furthermore, and as additional support, intake is depressed when rumen capacity is reduced (Forbes, 1996). A second theory, proposed by Illius and Jessop (1996), is that concentration and flow of nutrients and energy (specifically the volatile fatty acids produced by rumen fermentation) are involved in intake regulation. A third theory is that ruminants eat the amount of forage that results in optimum yield of net energy per unit of oxygen consumed (Forbes, 1996). The third theory is based on knowledge that differences in intake can be related to the efficiency of energy utilization (i.e. the animal's cost of processing feed; Ketelaars and Tolkamp, 1996). Controlled oxidation of food organic matter releases the energy necessary for maintaining the "fire of life". Oxygen and food consumption therefore, have a natural link in the release of energy for maintenance, growth, 
and production (Ketelaars and Tolkamp, 1996). While none of these theories are wrong, it is more likely that intake is a function of a combination of the three (Figure 2).

Intake is thought to be partially related to structural and chemical composition of the forage, forage availability, and physiological needs, as well as being influenced season and temperature (Vicini et al., 1982). Traditionally, the cell wall has been associated with bulk fill, with spatial filling of the reticulorumen being the limiting factor in regulating intake of moderate to low quality feeds (Felton and Kerley, 2003). Cell wall constituents, that represent the total fibrous part of the forage, limit intake when their proportion increases to more than 55$60 \%$ of the total dry matter (Van Soest, 1965). Limitations associated with forage quality reduce the time spent eating, but increases the eating rate. On pastures with limited forage, availability does not change the grazing patterns of animals significantly, but will cause the animals to rest less and have longer meals (Dulphy et al., 1980).

Intake regulation is complicated for different reasons, due, it part, to the body can store and recover energy in several different forms, such as glycogen and fat reserves (Mertens, 1991). Another factor adding to the complexity is psychogenic modulation. This component includes social interactions, management conditions, and feed characteristics, that can initiate or postpone a meal (Mertens, 1991). Factors affecting intake regulation range from species and gender, physiological state of the animal (maintenance, growth, pregnancy, 
lactation), body shape and size and animal health (Fahey et al., 1994; Dulphy et al., 1980; Figure 3).

Likewise, there are many external factors that affect a grazing animal's intake. These include environmental stress, production and management decisions, feed characteristics, and intrinsic forage components (Figure 4). It is hypothesized that palatability is the first determinant of what a moderately hungry animal will eat when presented with an abundant food supply (Grovum, 1988). Palatability, as described by Grovum (1988), includes olfaction and all of the oralpharyngeal sensations arising from eating food, and it excludes any of its postingestive effects. One proposed definition of palatability is "a plant characteristic eliciting a proportional choice among two or more forages conditioned by plant, animal, and environmental factors, which stimulate a selective intake response by an animal" (Nelson and Moser, 1994).

These forage components shown in Figure 4 have been implicated as having the greatest effect on intake and digestibility (Felton and Kerley 2003). The major internal factor limiting voluntary intake is the capacity of the reticulorumen and the portion of that capacity occupied by forage undergoing digestion (Vicini et al., 1982). Forage intake is related to fiber digestion, because this component of feedstuffs limits digestion and disappearance from the gastrointestinal tract (Mertens and Ely, 1979). Jung and Allen (1995) suggested that the cell wall fraction of the plant has a large impact on ruminant forage intake. Mertens (1987) defined this limiting cell wall fraction as the neutral detergent fiber (NDF) fraction of the plant. This NDF fraction is highly correlated 
with volume and bulk density of feeds (Mertens, 1987; Tjardes et al., 2002). The reason for this is that soluble constituents in feeds dissolve and contribute very little to the fill effect, the fiber fraction occupies space in the rumen. Neutral detergent fiber is the only fiber method routinely used that isolates all the fibrous components (cellulose, hemicellulous, and lignin; Mertens, 1987). Van Soest (1965) indicated that most of the space in the reticulorumen is occupied by the fibrous component of the feed, or the NDF fraction. Because the terms "fiber" and "cell wall" are often used interchangeably, it is necessary, in some cases, to define both of these terms. Jung and Allen (1995) defined the plant cell wall as "a complex biological structure containing many different molecules whose biosynthesis is controlled by enzymes encoded and regulated by genes". They further define fiber as "an analytical product having nutritional characteristics that describe those forage components that have low solubility in specific solvent systems and are relatively less digestible than starch". Two specific fiber fractions found in plants are neutral detergent fiber and acid detergent fiber. Because ruminant animals eat to meet their energy demands. When consuming diets high in cell wall content, they are often unable to meet the demand (Jung and Allen, 1995). Intake may also be limited by the amount of undigested feed residue in the gastrointestinal tract (Jung and Allen, 1995; Allen, 1996). Allen (1996) suggested that the ballast of undigested food residues in the gastrointestinal tract may limit intake. Van Soest (1965) found that voluntary dry matter intake (VDMI) of forages by sheep was more highly related to NDF than other chemical measures. It is thought that VDMI of a feed changes as the 
digestibility of that feed increases or decreases (Allen, 1996). It is also possible to change the VDMI by processing the feed. Options for altering VDMI include pelleting low quality forages and chopping silage more finely. The rationale is that a decrease in particle size reduces retention time in the reticulorumen (Allen, 1996). An experiment in sheep and summarized by Allen (1996), used pelleted leaf and stem fractions of three forages offered to sheep to show that retention time in the reticulorumen decreased 23.2 to $25.4 \%$ with a decrease in VDMI from 88 to $60 \%$ for pelleted vs. chopped leaf and stem fractions, respectively. In a second experiment, a 30\% reduction in VDMI of chopped alfalfa hay by sheep, was observed when $150 \mathrm{~g}$ of $7.0 \mathrm{~cm}$ long polypropylene fibers were placed into the reticulorumen. Insertion of the same weight of fibers that were $30 \mathrm{~cm}$ in length resulted in a 75\% reduction in VDMI (Welch, 1967). Results from this experiment show that it is not weight that causes reduced intake but the structure of the material. In plants, this intake limiting structure is NDF. Mertens (1987) reported that NDF is the only feed characteristics that has been used to predict the filling effects of forage. However, there is evidence that NDF, by itself, is inadequate for predicting fill for the following reasons; its filling effect varies with differences in initial particle size, particle fragility, and rate and extent of NDF digestion. Mertens (1987) reported that an animal will consume $1.2 \pm 0.1 \%$ of its body weight as NDF per day.

\section{Long and Short term Control}

Intake is regulated in the long and short term (Fahey et al., 1994, Mertens, 1987). Long and short-term intake are influenced by taste, smell, texture, and visual appeal (Mertens,1994). Emotional states, social interactions, and learning 
can all modify food intake (Fahey et al., 1994). Long-term regulation is described by average daily intakes over periods of time when nutrient requirements for maintenance and production are stable (Mertens, 1987). Long-term regulation occurs because stomach capacity is modified, within limits, by hypertrophy of organs and/or reduced constrictions associated with mobilization of internal adipose deposits to achieve a balance between distension stimuli and animal performance. Level of distension to satiety varies by physiological state or performance potential (Mertens, 1994). Short-term regulation involves events within the day that affect the frequency, size, and pattern of an animal's meals. Short- term regulation includes those factors that begin and end each meal (Grovum, 1988). Research on short-term regulation has been focused on specific nervous, chemical, and endocrine stimuli that trigger hunger and satiety signals (Mertens, 1987). During short-term intake regulation, stretch receptors in the reticulorumen signal the brain satiety center, which triggers the end of the meal (Fahey et al., 1994). Mechanisms for short-term regulation, meal initiation and cessation, are quite different from long-term regulation of body weight and performance over the animal's lifetime. At this point, the exact factors affecting intake, as well as the stimuli and mechanisms that regulate it, are not completely known. Intake regulation due to body weight is complicated because the body can store and recover energy in glycogen and fat reserves (Mertens, 1994). Energy stores provide a buffer that can stabilize both short and long term disturbances in intake. 


\section{Chemostatic/ Metabolic control}

Chemostatic regulation includes factors related to the metabolism of the feed being consumed. One can assume that the animal's maximum production capacity is dependent on the animal's genetic potential for such things as growth or lactation. Production potential varies throughout the animal's lifetime due to the interaction between genetic predisposition for growth and reproduction and physical and climatic environment. The animal's genetic potential is the maximum rate it can use and dispose of nutrients and its energy yielding substrates. This rate depends on how the energy is to be used, including protein or fat deposition, lactation, thermoregulation, or locomotion. An animal's required inputs depend on the level of production of output expected of the animals. Ideally, the balance between inputs and outputs should leave the state of body stores unchanged (Illius and Jessop, 1996). One form of chemostatic regulation is lipostatic feedback. Because feeding managers have to be careful not to feed their animals too long and thus allow excessive carcass fat to accumulate, and because we have fat cows, fat bulls, and fat steers, the concept of fat generating signals that subsequently limit intake is false (Grovum, 1988). One way fat may limit intake in ruminants is by decreasing the volume of digesta held in the reticulorumen. Additionally, there are conflicting ideas that plasma free fatty acids may increase or decrease intake (Grovum, 1988; National Research Council, 1996). Some researchers believe that free fatty acids control intake, while others do not; therefore this area of intake control is controversial (Journet and Remond, 1976). In support of this theory, Journet and Remond (1976) observed that, after calving, a high level of plasma free fatty acids (FFA) 
corresponds with low intake, and intake increased until plasma FFA decreased. Additional data indicate that plasma FFA's decrease greatly after a meal, and after feeding, blood FFA were correlated with feed intake during subsequent feedings (Journet and Remond, 1976). Baile and Forbes (1974) suggested that prostaglandins released during lipid mobilization may play an important role in regulation of feed intake. Leptin and insulin interact to regulate a specific level of body fat (Fisher, 2002). The demand for feed by a healthy animal is related to the animal's ability to metabolize feed and varies widely with animal condition. An imbalanced diet can contribute to an increase or decrease in feed intake (Fisher, 2002). For example, balance is especially important with regard to energy and protein intake because the animal integrates multiple nutritional signals. A large dietary imbalance may reduce intake.

Baile (1975) conducted research with sheep to determine if there were any blood components that could suppress or elicit feeding. These experiments involved the exchange of jugular blood between pairs of sheep, one satiated and one hungry. Upon receipt of the blood from the hungry sheep, the satiated animals began to eat, and there was a reduction in intake in the hungry animals receiving blood from the satiated animals.

Volatile fatty acids (VFAs), the predominant energy source in ruminants, are produced through fermentation of carbohydrates in the rumen by the action of rumen bacteria. Hart and Glimp (1991) observed increases in jugular, portal, and ruminal plasma VFA concentrations after feeding. Evidence suggests that epithelial receptors in the rumen wall that are sensitive to VFAs. Cole (1991) 
observed a decrease in feed intake when ruminal fluid from fed lambs was transferred to fasted lambs. The depression in feed intake was attributed to the presence of VFAs in the rumen fluid from the fed lambs.

\section{Psychogenic regulation}

Intake is also limited by the external environment interacting with the animal's internal limits such as rumen capacity (Figure 1). Forbes (1996) states that animals seem unwilling to spend more than twelve hours per day eating, and Burns et al. (1994) state that ruminants may have 10 to 20 meals per day. Neither of these statements mean that there is a sudden fixed end to eating when a given number of hours have passed or meals have been consumed. Instead, if the animal is grazing sparse pasture, for example, rate of eating will be a limiting factor in a given amount of time spent eating. Because it is unlikely that a given number of hours passing triggers the animal to stop eating, it is more likely that the limit is influenced by the animal's nutrient demand, time required for rumination, and other important (to the animal) activities. The psychogenic regulation of food consumption (Figure 5) involves the animals' behavioral and metabolic response to inhibitory or stimulatory factors in the feed or feeding environment that are not related to the feed's energy value or filling effect (Fahey et al., 1994, Mertens, 1987). Taste, smell, texture, and visual appeal of a feedstuff can affect both short and long term intake regulation. The most common feed characteristic that affects this type of regulation is palatability of the feed. Palatability may also be described in terms of acceptability, preference, selective grazing, and relish conditioned by sensory impulse (Forbes, 1996). In the case of psychogenic regulation, a simpler, and less restrictive definition of 
palatability may be necessary. Along with palatability, an animals feeding behavior is also subject to previous experience. Being in a group situation, an animal is more likely to start eating, at any given level of nutrient status and visceral stimulation, if other animals in the group are eating. Most animals are also more likely to eat food for which sensory properties are familiar to them, and have not previously led to abdominal discomfort (Forbes, 1996). In a group situation, social order may also influence the amount an animal consumes. Animals at the lower end of the social order may be unable to meet their nutrient requirements even though ample feed is available. If feeding or bunk space is limited, dominant animals may limit others access to a feed (Welch and Hooper, 1988).

\section{Physical feedback}

It is believed that intake regulation in ruminants occurs primarily at the level of the rumen. Forbes (1996) describes abdominal receptors, sensitive to mechanical, chemical, and temperature stimuli, that transmit information via the vagus nerves and sympathetic nervous system to the hypothalamus. Fisher (2002) suggests that a key feature of regulatory feedback is the physical feedback mechanism, and believes that understanding this mechanism depends on understanding key parts of the ruminant digestive system.

Grazing ruminants have small parotid (salivary) glands, compared to an animal consuming a concentrate diet, that produce salivary buffers. The small parotid glands indicate a dietary preference for grasses. Because forage digestion and fermentation does not caused as drastic fluctuations in rumen $\mathrm{pH}$ as grain based diets, there is not as much of a need for buffers supplied by saliva 
from the parotid glands. Grazing animals also have a larger rumen and slower rate of passage than animals on a grain based diet, with the results that there is an increase in ruminal fermentation, small distal fermentation chambers and spiral colons. Compared to ruminants receiving a diet high in concentrates, grazing ruminants are more specialized for foregut fermentation with a slower rate of passage (Fisher, 2002). Ruminants must be able to process large amounts of fibrous feeds. Microbial fermentation allows ruminants to extract much more energy from roughages than mammalian enzymes alone, and to convert non-protein nitrogen to microbial protein (Allen, 1996). The reticulorumen is generally thought of as the site in the gastrointestinal tract where distension limits intake. Allen (1996) reports that tension receptors are located primarily in the reticulum and cranial sac. Explaining a mechanism whereby intake is limited.

Nonetheless, because intake regulation is critical to the survival of all animals, it is illogical to assume that a function critical to life could be controlled by a single mechanism. Assuming intake is controlled by one mechanism would question the survival of species throughout evolution, as animals were presented with a variety of environmental changes (Mertens, 1991).

\section{Predicting Intake}

The first half of the century saw the development of a progression of techniques for estimating intake in grazing animals. The second half set about putting these developments to use. There are several techniques for estimating intake on pasture. These methods are based on the use of internal or external 
markers, ingestive behavior, disappearance of herbage mass, prediction from forage characteristics, and animal performance. Techniques based on the use of markers or on ingestive behavior are considered suitable for estimates of intake by individual animals, and techniques based on the disappearance of herbage mass, prediction from forage characteristics, or calculations of energy requirements for observed animal performance are suitable estimates for groups of animals on a pasture (Macoon et al., 2003). A conventional approach to determining voluntary intake would be to harvest the forage and feed it to penned animals. Unfortunately, this method does not allow the animal to select specific plants or portions of plants as it would during grazing, thus harvested forage may not be representative of the forage actually consumed by the animals (Galyean, 1997). The most successful and widely used methods have been those based on estimates of digestibility of consumed forage and fecal output. It is possible to estimate a grazing animal's intake through manipulation of the following equation:

DDM $=1-(\text { fecal output } x \text { intake })^{-1}$ into: Intake $=$ fecal output $\times(1-\text { DDM })^{-1}$ (Lippke, 2002; Dove and Mayes, 1996).

In order to determine the fecal output of an animal, total collection is necessary. There are two primary ways of determining total fecal output. The first is through the use of total collection bags and harnesses. There are several disadvantages associated with this practice. The biggest is in the labor requirement, not only in the actual collection, but also in the training and maintenance of the animals to accept the collection bags as well as daily animal 
handling. Another problem is that handling and acquiring the animals once or twice daily to empty the bags has the potential to alter grazing behavior, and in turn, alter the animal's intake and fecal output (Lippke, 2002; Hatfield et al., 1993; Dove and Mayes, 1996, Van Keulen and Young, 1977). A final disadvantage is the possibility of feces escaping the collection bags (Lippke, 2002). The only way to account for any of these potential problems is to, by chance; see feces escaping the collection bag. Hatfield et al (1993) suggest that animals fitted with total collection bags may lose weight, as a result of reduced intake. The biggest advantage to using collection bags and harnesses is that results are obtained quickly and only DM and ash determinations are required (Burns et al., 1994). A second method of total collection, utilized and described by Momont et al. (1994), is to house the animals in individual pens and scrape the floor several times per day. Obviously, though, animals would not be in a grazing environment.

Alternative methods rely on fecal sampling rather than total collection. Grab samples can be taken directly from the animal (Gekara et al., 2001; Momont et al., 1994). Baker et al. (1988) describe a method where feces, in a field, were marked with a dusting of ground limestone. The next day, unmarked feces were sampled, and then marked with a dusting of ground limestone. This method eliminates animal handling and potentially disrupting the animal's natural grazing patterns.

\section{The Use of Markers to Predict Intake}

All of these methods developed to estimate intake of grazing animals focus on the measurement of fecal output and forage digestibility using external 
or internal markers (Lippke, 2002). Accurate determination of digestibility depends on the use of markers that flow with the material being measured (Ohajuruka and Palmquist, 1991). A problem noted by Sunvold and Cochran (1991) was that markers applied across a wide range of forages or in different laboratories frequently produced erratic results. Another problem, pointed out by Duncan et al (1999) is that errors made in the estimation of fecal output by an animal will carry through to errors in the estimation of intake.

Lippke (2002) and Galyean (1997) suggested that markers should be: 1) inert, with no toxic, physiological, or psychological effects; 2) neither absorbed nor metabolized within the $\mathrm{Gl}$ tract and therefore be recoverable from either raw or processed food; 3) should have no appreciable bulk, mix well with the animal's usual food and remain uniformly distributed in the digesta; 4) have no influence on the microflora of the GI tract that is significant to the host; 5) be in sufficient quantities that allow ready and precise qualitative measurements; and 6) have chemical properties that make it discernible throughout the digestive phases. Unfortunately, none of the markers currently in use satisfy all these criteria. However, effective measures ban be made by selecting a marker appropriate for experimental conditions.

Two general methods of using markers are chemical modification with an external marker, and the use of an internal marker that is endogenous to the plant. There are associated problems with each of these. Two of the biggest issues are the possibility that chemical modification can change the digestibility, density, and rate of passage of the feed, and indigestible residues may be 
variably digested or solubilized and are chemically ill defined (Ohajuruka and Palmquist 1991).

\section{External Markers}

External markers must be added to the feed or dosed in one of three ways; a single large dose at the beginning of the trial; uniform daily doses; or the use of a controlled release device (CRD) that remains continually active throughout the study (Lippke 2002). Two external markers are chromic oxide and ytterbium chloride. Chromic oxide is the most commonly used, but it has some associated problems. The biggest is that it flows variably with liquid and particulate matter (Ohajuruka and Palmquist, 1991). Because it is a dense powder, chromic oxide also moves through the GI tract independently of undigested particles in the diet. A fraction of the $\mathrm{Cr}_{2} \mathrm{O}_{3}$ may become sedimented in the reticulorumen and this fraction may be transferred sporadically to the lower gastrointestinal tract (Merchen, 1988; Lippke, 2002; Momont et al., 1994; Mertens and Ely, 1982). There are many reports of fecal concentrations of $\mathrm{Cr}_{2} \mathrm{O}_{3}$ exhibiting strong diurnal variations (Lippke, 2002; Dove and Mayes, 1991; Kiesling et al., 1961; Nelson and Green, 1961; Kozloski et al., 1998; Kotb and Luckey, 1972). These variations may be reduced by administering a minimum of two doses daily, and research has shown that the greatest reduction in variation resulted from six daily doses (Lippke, 2002). Nonetheless and due to the amount of animal handling and potential associated problems, this is not a practical option. Another solution to reduce diurnal variation is the use of a CRD. Despite its advantage of virtually eliminating the variation, release rate of a CRD varies 
under varying dietary conditions (Lippke, 2002; Dove and Mayes, 1996).

Chromic oxide may be administered in the form of a bolus. The release of $\mathrm{Cr}_{2} \mathrm{O}_{3}$ from the bolus, as suggested by Momont et al (1994), may be related to water kinetics in the rumen. Ruminal fluid dynamics are related to forage type causing differences in $\mathrm{Cr}_{2} \mathrm{O}_{3}$ release rates due to diet composition. Research conducted by Momont et al. (1994) with lambs showed that higher release rates are associated with less digestible feeds. Lambs were fed either meadow hay $(\mathrm{DMD}=58 \%)$ or fresh cut clover $(\mathrm{DMD}=77.5 \%)$ and they had $\mathrm{Cr}$ release rates of 68.1 and $54.8 \mathrm{mg}$ of $\mathrm{Cr} /$ day respectively. Two problems with the bolus were bolus regurgitation and an unexplained failure to release $\mathrm{Cr}_{2} \mathrm{O}_{3}$ in the rumen (Momont et al., 1994).

Some rare earth elements have been used as particle flow markers. These markers can work as long as their concentration does not exceed the binding capacity of the marked particulate. The binding sites of most feedstuffs have limited binding capacities for rare earth elements (Merchen, 1988; Pond et al., 1985). Ytterbium, the most commonly used rare earth element is usually administered with a single dose. One problem with ytterbium is that it binds with varying affinity to organic matter, especially fiber (Lippke, 2002). Changes in physiochemical conditions during passage through the gastrointestinal tract, particularly at an acidic $\mathrm{pH}$ such as occurs in the abomasum, enhance migration and solubilization of rare earth elements (Merchen, 1988). 


\section{Internal Markers}

The major problem with internal markers as a whole is that a majority of those tested cannot be analyzed as discrete compounds and their inconsistencies in herbage and feces can lead to errors in the estimation of digestibility and intake (Mayes et al., 1986). Another problem with using internal markers for grazing animals is that it is often difficult to obtain a representative sample of what the animal is consuming (Reid et al., 1949). Internal markers are naturally occurring entities within the plant. Two specific markers are indigestible neutral detergent fiber (INDF) and alkanes.

Acid Insoluble Ash (AIA) has also been frequently used in equine studies, but a problem arose in the analysis because it is not a discrete chemical entity (Ordakowski et al., 2001).

Indigestible neutral detergent fiber (INDF) of forages is the portion of the cell wall that is insoluble in neutral detergent solution, and it is completely indigestible under physiological conditions in the reticulorumen (Felton and Kerley 2003).

Dove and Mayes (1996) outlined three major disadvantages to using in vitro methods. First, the results are often applied to a different class of animals, or animals with a different level of intake than those used to establish the in vitro/ in vivo digestibility calibrations. Secondly, in vitro digestibility analysis results in a single value that is then applied to all animals, when in fact digestibility may differ substantially between animals. And lastly, the in vitro digestibility cannot account for possible interaction between dietary components, such as protein and starchy 
foods. This last one usually only presents a problem in animals receiving supplementation. Their use as markers for digestibility determination in grazing ruminants offers potential advantages over other methods, such as in vitro and index techniques, in that digestibility can be directly estimated in vivo (Mayes et al., 1986). Felton and Kerley (2003) address several problems specific to using INDF as a predictor of intake. First, the determination of INDF is time consuming and can often take up to seven days before any results are obtained. A second problem is the risk of contamination, especially when fistulated animals are used. Last, if incubations are performed in vitro, a build up of fermentation products may limit fiber digestion. Because fiber digestion typically proceeds from cut or broken edges of cell walls and not from intact surfaces, lack of uniform particle size among fermentation substrates may be partially responsible for the variable and generally less than complete recovery of INDF in feces (Lippke et al., 1986).

Acid Insoluble Ash (AIA) has been identified as having potential as a digestibility marker. Van Keulen and Young (1977) reported an average recovery of residue of $99.8 \%$, and that AIA is superior to chromic oxide as a marker in swine diets. In experiments using $2 \mathrm{~N}, 4 \mathrm{~N}$, and concentrated $\mathrm{HCl}$ to isolate the insoluble organic portion of a feed, the $2 \mathrm{~N} \mathrm{HCl}$ procedure was easiest. Furthermore, ashing the sample prior to acid treatment removed the organic matter, thus reducing the strength of acid required and avoiding the problem of unpleasant odors which occur when feed or feces are digested with acid (Van Keulen and Young, 1977). Using $2 \mathrm{~N} \mathrm{HCl}$ may be safer than higher concentrations because of the lower normality of the acid. Potential problems 
with using AIA are contamination of the ingesta with soil or dust, or the consumption of bedding by the animal that can all lead to biases. Van Keulen and Young (1977) stated that care must be taken if samples are obtained off the ground to avoid contamination, but problems of contamination may be avoided if fecal grab samples are taken. Despite disadvantages, AIA does offer some distinct advantages including no need for special confinement or restraint of the animals; a single feed and fecal sample can be used to estimate feed digestibility; AIA occurs in common feedstuffs at readily measurable levels; and lastly, laboratory procedures are not difficult, nor time consuming (Van Keulen and Young, 1977). Acid insoluble ash may also act as a reliable marker because minimal diurnal variation is noted (Merchen, 1988).

Naturally occurring, long chain n-alkanes may be used as internal markers to determine intake and digestibility of plants (Ohajuruka and Palmquist 1991). Alkanes are saturated, long chain fatty acids from 19 to 35 carbons in length, that are discrete, indigestible compounds found in plant cuticular wax (Ordakowski et al., 2001; Mayes et al., 1986). Typically, shorter chain length alkanes are detected in smaller quantities than long chain alkanes (Dove and Mayes, 1991). The three most common, naturally occurring alkanes are nonacosane $\left(\mathrm{C}_{29}\right)$, hentriacontane $\left(\mathrm{C}_{31}\right)$, and tricontane $\left(\mathrm{C}_{33}\right)$. Mayes et al (1986) began a series of experiments on the use of alkanes as internal and external markers for estimating digestibility and intake of forage. Their first experiment used perennial ryegrass fed to lambs to examine the suitability of odd chain alkanes, $C_{27^{-}} C_{35}$, and dosed even chain alkanes, $\mathrm{C}_{28^{-}} \mathrm{C}_{32}$, as internal and external markers under 
several dietary conditions. Fecal recovery increased from 71 to $93 \%$ with increasing chain length, recovery of dosed alkanes appeared slightly higher than the recovery of naturally occurring alkanes, and recovery was unaffected by level of intake and diet composition. Their work also showed that recovery rates of dosed $\mathrm{C}_{32}$ and naturally occurring $\mathrm{C}_{33}$ were nearly identical, at about $89 \%$. Additional work has shown that recovery rates of the alkanes from the gastrointestinal tract and feces of ruminants is generally incomplete, recovery appears to be related to chain length, with percent recovery increasing with chain length (Lippke, 2002; Duncan et al., 1999). Recovery approaches $100 \%$ at about $\mathrm{C}_{31}$ (Lippke, 2002).

In order to reduce the labor required during daily or more frequent dosing, an alkane CRD was developed and tested in sheep. The biggest advantage of the CRD is that it substantially reduces daily disturbances to the animals and minimizes the chance of diurnal variation (Dove and Mayes, 1996).

A big advantage of using alkanes as predictors of intake was suggested by Mayes et al (1986). They suggested that the microbial population of the ruminant digestive tract has little influence on the metabolism of these herbage alkanes. Therefore, intake estimates appear unaffected by feeding level or by concentrate in the diet. Based on these characteristics of alkanes as markers, unbiased estimation of herbage intake should be possible in animals receiving supplementary feed. Even chain, dosed alkanes may help reduce the amount of animal handling because they may be administered by bolus, that gradually releases a known amount of marker (Appenddu and Brown, 2002). Other 
advantages of using alkanes, because they are discrete chemical entities, include no need for marker preparation, so costs are reduced and compared with other markers, such as acid insoluble ash (AIA), they are relatively simple to prepare and analyze using gas chromatography (Ordakowski et al., 2001). It is often difficult to apply a marker over a wide range of forages, but because each species of plant has a different profile of alkanes, it may be possible to determine diet composition from the alkane patterns found in the feces (Duncan et al., 1999). Several advantages, outlined by Dove and Mayes (1996) for using alkanes as a marker include: 1) the method allows for between animal variation in diet digestibility and therefore provides estimates of individual intakes; 2) the method can accommodate the feeding of supplements to the animals, provided intake of supplement are known; 3) alkanes can be used to obtain individual intakes in group housed animals; and 4) compared to other analytical procedures such as $\mathrm{Cr}_{2} \mathrm{O}_{3}$ and invitro techniques, that require separate procedures, alkanes only require a single analytical procedure.

A disadvantage is that their incomplete recovery may limit their use as an internal marker (Ohajuruka and Palmquist 1991). As chain length of alkanes decreased, accuracy also decreases. Results from Duncan et al (1999) showed that when using sprayed on even chain alkanes, adjacent to dosed $\mathrm{C}_{34}$ alkanes tended to produce more precise intake estimates then when compared to $\mathrm{C}_{26}$ alkanes and adjacent even chain alkanes. This may be because the increase in recovery of alkanes with C-chain length increases as C-chain length increases. Intakes are less likely to be accurate when shorter C-chain length n-alkanes are 
used compared to longer chain n-alkanes. However conflicting, research has shown that there may be incomplete recovery of alkanes in fecal matter due to absorption from the small intestine (Dove and Mayes, 1996).

Dove and Mayes (1996) pointed out that alternative methods to compare the validity of alkanes to be no more reliable, or may even be inferior. Lastly, a concern with any technique is that factors that may influence the reliability of the technique being used with grazing animals, such as within and between day variations in feeding patterns have not been extensively studied. A main precaution is that the diet samples must be representative of what is consumed by the experimental animals (Dove and Mayes, 1996).

\section{Conclusion}

It is unlikely that production of slaughter cattle on range or grass will replace feedlot production. Although it does provide another marketing channel for cattle producers and another choice of meat for consumers. Creating a niche market for forage finished beef will give producers an alternative to that sending their cattle to a feedlot to be finished. This will also raise the possibility of greater income for producers. Undoubtedly, we will always have feedlot beef in this country, because demand for highly finished beef by wealthier clientele, in select restaurants and hotels will always exist. Albeit this demand for high quality beef is not relegated to wealthy customers. However, with the growing health concerns of consumers, a growing market also exists for those who prefer a leaner cut of beef. The rapid growth of the fast food beef industry has created a large market for lean beef that can be produced at lower cost on high quality 
pasture (Hoveland, 1986). Consumption of imported beef is an indication of preference for this type of product, and the United States producers should be competing more strongly for a share of this market. One reason foreign countries can undersell United States producers is that they depend heavily on grazed forages rather than on more expensive concentrates for production (Turner and Raleigh, 1977). To become more competitive in this niche market, United States producers must become more dependent on grazed forages as well.

Development of grazing systems for forage-finished animals requires more research on forage quality, especially during the winter months. Since cool season grasses vary in quality, it may be necessary to combine several grass species, rather than relying on one or two species to meet the growth requirements of cattle. Because the limited amount of research done has focused on native forages, another possibility may be to look into other grass species, in addition to than the widely used tall fescue, that are suited for stockpiling and retain quality into the cooler fall and winter periods. It is also necessary to determine the animal genotype best suited for forage finishing. Forage finishing may be more successful using smaller framed, early maturing animals. Another possibility may be to open up a niche market where producers will not be penalized for presented lighted weigh animals for slaughter.

There is no single factor that can be stated as the controler of intake. Intake control, instead, a complex interaction between physical, psychogenic, and physiological characteristics of the plants and animal. Because of this 
complex interaction, there is still no reliable method to predict intake in grazing animals. The predominant method that has been used combines total fecal collection along with the use of either an external or internal marker. Typically, the external markers used are rare earth elements such as chromium or ytterbium. Internal markers being researched include long chain alkanes, INDF, and AIA. Most of the work on markers has been carried out it homogenous swards. More research is needed to examine marker reliability across grass species. In order to accurately measure and predict forage intake, a combination of both internal and external markers may be necessary.

Based on the literature reviewed, we set out to do two experiments in order to evaluate variability in the consumption of intake markers commonly used to predict forage intake. The markers investigated were NDF, INDF, and AIA. During the winter period, four potential forage grazing systems were also examined, comparing animal performance. Methods of assessing animal performance were ultrasonography and animal weight changes. 


\section{Materials and Methods}

\section{General}

Weather data, daily temperature and precipitation, were collected for Experiments 1 and 2. For Experiment 1, weather data was obtained from the Morgantown, WV weather station located at the Morgantown Airport. Daily precipitation for Experiment 1 was collected from www.wunderground.com. Weather data for Experiment 2 was obtained from the weather station located at the Reedsville Farm (Preston County, WV). For Experiment 2, a map was made of the treatment areas by walking the fence lines of each treatment area with a GPS unit, and transferring data into ArcMap 9.1 (2004). The objective of these two experiments was to evaluate commonly used methods of forage intake prediction in a controlled environment, as well as a grazing environment. Following this, the performance of steers in four winter forage feeding systems was evaluated.

\section{Experiment 1: Predicting Intake in a Controlled Environment}

\section{Objective}

To compare variability in commonly used intake markers (NDF, Acid Insoluble Ash (AIA), Indigestible Neutral Detergent Fiber (INDF), and alkanes) between two types of hay (Timothy or Orchardgrass) chopped to two different lengths (short or long). Previous research has shown that processing treatments, such as grinding, may alter voluntary intake. 


\section{Experimental Area and Animals}

Experiment 1 was conducted at the West Virginia University Livestock Farm, located in Morgantown, West Virginia. Experiment 1 consisted of four period during 2004. Crossbred yearling steers ( $\mathrm{n}=\mathrm{six}$; average BW $319 \mathrm{~kg}$ at the start of Experiment 1) were trained to accept halter and fecal harness prior to initiation of Experiment 1. Steers were assigned randomly to treatment. The animals were divided into two groups of three animals each and housed in drylots in two adjacent pens ( $4.88 \times 12.19$ meters), sharing a common water source. Each pen had a 4.88 meter long concrete bunk providing 1.63 meter per head, in which the steers were fed. Approximately $65 \%$ of each pen was under roof. Animals had free access to water. A trace mineral block was available during the acclimation period, but was removed on day 6 . This was done so ash and AIA values would not be skewed by the mineral intake. Experiment 1 was conducted from May 28 through July 30. Trial 1 consisted of two periods, running from May 28 through June 8 and June 19 through July 1, respectively. Trial 2 consisted of two periods, running from July 6 through July 18 and July 18 through July 30 , respectively.

\section{Treatments}

Treatments for Experiment 1 was timothy (Trial 1) or orchardgrass hay (Trial 2) chopped to two different lengths, (fine), approximately 1 inch, and (coarse) approximately 5-6 inches in length. Timothy hay, grown in New York 
and orchardgrass hay, grown at the Reedsville Farm, Preston County, WV, were chopped, in a KFM Fabrication Ltd (KFM Fabrication Ltd., Wiltshire, UK) and Vermeer BP7000 (Vermeer Manufacturing Company, Pella, lowa) chopper, respectively, before the experiment and stored under roof. Respective hays were fed ad lib to the steers for trials 1 and 2 during each experiment.

Hay was offered at $3 \%$ of average pen body weight on the first day and subsequently offered at $110 \%$ of the previous days ad lib intake for the remaining days of the trial. This was done to ensure the animals were truly being fed ad lib and allowed animals to select certain plants and plant parts without creating too much waste. Orchardgrass was fed in the same manner as described for Trial 1.

\section{Trial Schedule}

As consistent with previously reported literature, each period was twelve days long, the first eight being allotted for an adjustment period, and the final four days for collection. The adjustment period allowed animals to become accustomed to the hay so variations in intake would be reduced. A four day collection period was used to minimize day-to-day variability in excretion. This period also allowed for animals to consistently consume $\mathrm{Yb}$ labeled oats, allowing for reduced variability in $\mathrm{Yb}$ excretion. During the final four days of each trial, samples of hay feed and orts were taken as well as fecal samples. Steers were weighed on days 1 and 12 of each trial. Weights were averaged and used to report intake expressed as a percentage of body weight. Day 1 was designated as the start of each trial. Animals were fitted with total fecal collection harnesses and bags on day 6 . Bags were emptied twice daily at twelve-hour 
intervals. At each collection, bags were changed and weighed to calculate total fecal output. Fecal samples were taken at $10 \%$ of the total fecal output. Hay offered and orts refused were weighed daily to determine pen intake. Hay samples were collected on days 7-12 and orts were sampled on days 8-13. A protocol of basic experimental activities is outlined in Figure 6 .

\section{$\underline{\text { Yb Dosing }}$}

Beginning on day 1 of each trial, individual steers were fed $100 \mathrm{~g}$ of $\mathrm{Yb}$ labeled oats per day, split equally between two feedings were fed to steers. Animals were tied and offered oats, and left tied until all animals consumed all oats offered in order to ensure no animal was consuming more than that $50 \mathrm{~g}$ per feeding. Oats were labeled with $\mathrm{Yb}$ by spraying them with $\mathrm{a} \mathrm{YbCl}_{3}$ solution as described by Baker et al. (1988). Oats were offered at daily twelve-hour intervals, (6 AM and $6 \mathrm{PM})$. Oats were mixed with a small amount of dry molasses or corn to ensure the consumption of the whole dose. Animals were watched at each feeding to ensure that all oats were eaten.

\section{$\underline{\text { Analytical Methods }}$}

\section{Sample Preparation and Analysis}

Hay and fecal samples were dried at 38 degree $C$ and were ground to pass through a $1 \mathrm{~mm}$ screen in a Wiley Mill (Brabender Measurement Control System, Germany). Upon collection of fecal samples, they were immediately placed in a 38 degree oven to dry. Daily hay samples collected at random during 
the sample period were mixed thoroughly and composited within each pen for analysis. Samples were composited by grinding daily hay samples and mixing in an equal percentage basis.

All analysis described were performed using duplicate samples. Dry matter of hay and fecal samples was determined by drying $1 \mathrm{~g}$ samples in a 100 degree C oven for 24 - 48 hours and recording the weight change. Samples were then ashed at 450 degrees $C$ for at least 4 hours to determine the organic matter composition. Sequential NDF and ADF content was determined by a modification of the Ankom@ fiber analysis procedure (Van Soest, 1991). Following NDF and ADF determination, samples were assayed for ADL content (Goering and Van Soest, 1970). Total $\mathrm{N}$ in forages was determined using the Kjeldahl method, with crude protein being calculated by multiplying the percent $\mathrm{N}$ by 6.25 .

Fecal samples were composited by animal by day and analyzed for Acid Insoluble Ash (AIA) using the procedure described by Van Keulen and Young (1977), Yb (Karimi et al., 1987), and Indigestible Neutral Detergent Fiber (INDF; Felton and Kerley, 2003).

Acid insoluble ash, INDF, and Yb were assayed in triplicate. Indigestible NDF was determined by placing triplicate $7 \mathrm{~g}$ samples in $10 \times 20 \mathrm{~cm}$ Forage in vitro bags (Part number R1020; ANKOM Technology) and sealed using a impulse heat sealer. In vitro bags were then inserted in the rumens of two dry, fistulated dairy cows, being fed a forage based diet, and incubated for 120 hours. The dairy cows were fed the same orchardgrass hay the steers received. Upon 
removal from the rumen, bags were washed until water ran clear and placed in a 55-degree $C$ oven until dry. Once samples were dry, sequential NDF, using sodium sulfite, and ADF fiber analysis was run on the digested samples and INDF was determined as the indigestible residue remaining after extraction. Acid insoluble ash was determined using the procedure outlined by Van Keulen and Young (1977). Five g of sample (DM was previously determined) were placed in the ashing oven overnight at 500 degrees. Samples were cooled and weighed. The beakers and samples were transferred to a $600 \mathrm{~mL}$ Berzelius beaker $100 \mathrm{~mL}$ of $2 \mathrm{~N} \mathrm{HCl}$ (EMD Chemicals) was added. The acid and ash were boiled for five minutes on a crude fiber digestion apparatus. The boiled sample was then filtered through Whatman number 41 filter paper and washed clean with boiling distilled water. Samples were ashed again overnight at 500 degrees. Remaining sample was weighed and AIA was calculated using the following formula.

Acid Insoluble Ash $=(\mathrm{Wf}-\mathrm{We}) / \mathrm{Ws} * 100$ Where Wf equals ashed sample weight after digestion; We equals original beaker weight; and Ws equals original dry sample weight.

Ytterbium concentration was determined by atomic absorption spectrophotometry and was used to estimate fecal output. To correct for background interference, standards were made using $\mathrm{Yb}$ free feces. Oats randomly selected from each trial were assayed for $\mathrm{DM}$, ash content and $\mathrm{Yb}$ concentration. The grams of organic matter per day excreted by each steer was calculated by the following equation:

Marker consumed (g/d)

Marker concentration in feces (g/g DM) 
Digestibility of forage samples were determined by incubating 7 grams of sample in the rumen of a fisulated dairy cow, which was acclimated to a forage based diet, for 48 hours. Digestibility and INDF were determined at the same time. Difference was recorded and digestibility was calculated. Dry matter intake was calculated from fecal output and forage digestibility estimates. Variability in intake of the various internal markers were determined.

\section{Statistical Analysis}

Data was summarized and means were presented. Statistics were calculated using the SAS computer program (SAS Inst. Inc., Cary, NC). The experimental unit for Experiments 1 was pen. Data were analyzed using the GLM procedure of SAS. Pen, hay, and processing treatment were used as classes for analyzing. P-values less than 0.05 were considered significant.

\section{Experiment 2: Winter Feeding Trials: Predicting Intake in a Pasture Setting}

\section{and Production of Steers in Winter Forage Systems}

\section{Objective}

Objective 1 was to compare different forage systems (grazed permanent stockpiled pasture (Kentucky Bluegrass/Naturalized pasture) and first cutting wrapped hay fed on pasture; grazed aftermath hay fields (Orchardgrass) and first cutting wrapped hay fed on the hay field; grazed aftermath hay fields (Tall Fescue) and first cutting wrapped hay fed on the hay field; and grazed aftermath hayfields (Orchardgrass) and first cutting dry hay fed in a drylot with soybean hull 
supplementation) for wintering cattle. Average daily gain and ultrasonography was used to assess the potential of the four winter forage species. Objective 2 was to compare variability in commonly used intake markers (NDF, INDF, and AIA) in animals grazing stockpiled forages and harvested hay.

\section{Experimental Area and Animals}

This experiment was conducted at the Reedsville Experimental Farm in Preston County, WV. Forty-eight Angus-Hereford crossbred fall-weaned calves (initial body weight averaged $250 \mathrm{~kg}$ ) were assigned at random to one of four treatments, each replicated three times. Four calves were assigned at random to 0.81 ha ( 2 acres) of grassland for each treatment/ replication. A grazing period (December 2, 2004- February 15, 2005) was followed by a hay-feeding period (February 15, 2005- April 4, 2005). During the first period (grazing), available forage was strip grazed, which allowed the animals access to enough area to supply feed for approximately 7 days. Hay was fed during this period only when weather conditions restricted access to forage. During the second period, the animals were fed wrapped or dry hay. Animals were allowed free access to water and trace mineralized salt blocks. Calves were weighed every 28 days of the winter-feeding period. Ultrasonography for back and rump fat, rib eye area (REA), and intramuscular fat (IMF) also took place at the start and conclusion of the winter-feeding period. 


\section{$\underline{\text { Treatments }}$}

The four treatments were: 1) grazed permanent stockpiled pasture, composed mostly of Kentucky bluegrass with some orchardgrass and timothy (Kentucky Bluegrass/naturalized pasture; Native) and first cutting wrapped hay fed on pasture; 2) grazed aftermath orchardgrass hay fields (Orchardgrass; OGHaylage) and first cutting wrapped hay fed on the hay field; 3) grazed aftermath tall fescue hay fields (Tall Fescue; TF) and first cutting wrapped hay fed on the hay field; and 4) grazed aftermath orchardgrass hayfields (Orchardgrass; OGHay) and first cutting dry hay fed in a drylot with soybean hull supplementation. All four treatments were replicated three times, with plots being located in different places on the farm. Once the grazing period was completed, the animals on treatment four were moved to the West Virginia University Livestock Farm, Morgantown, WV, and housed in drylot pens. For treatments 1,2 , and 3 , the same first cutting haylage was used. Forage was harvested at anthesis, wilted, and wrapped. First cutting for treatment 4 , of the same botanical composition as that used for treatments 1, 2, and 3, was saved as dry hay and harvested after anthesis, as weather permitted. At the commencement of the hay feeding period, to provide the animals with hay, one round bales was split between the three plots for each treatment. The round bale was unrolled and fed on the ground. All hay was harvested at the Reedsville Farm, Preston County, WV. Treatments were designed to provide animal gains of $0.5 \mathrm{~kg} / \mathrm{head} / \mathrm{d}$. After the first 28 days data from one calf, from the fescue 
treatment, was removed from the experiment due to safety concerns. Because the average gains for the OGHaylage and Native treatments fell below the projected $0.5 \mathrm{~kg} / \mathrm{d}$ following the third weigh period, animals were supplemented daily with soyhulls. Expected intakes were calculated at $2 \%$ of the average body weight for the plot. Keeping within the upper limit of supplementation allowed in forage fed animals, steers were given $20 \%$ of this expected intake as soyhulls (Table 13). Soyhulls were fed in plastic feed bunks, located near the automatic waterers of each plot.

\section{Trials and Sampling}

Five of the six steers previously described, in experiments 1 and 2, were used to evaluate intake in a pasture setting throughout the winter feeding period. These animals were the designated tester animals. Experiment 2 consisted of three trials; pasture/grazing, and no hay was offered, using five steers; fescue hay, using three steers; and orchard grass and native hay, using five steers. The first trial was conducted from December 10, 2004- December 22, 2004, while the animals were grazing pasture. Grass samples were taken by observing tester animals while grazing and clipping a representative sample of what the animal was grazing. To obtain fecal samples the five tester steers were randomly assigned to plots using a random number generator in Microsoft Excel (Microsoft). These five animals were already trained to accepts halters and fecal bags. Trials were twelve days in length, consisting of an eight-day acclimation period and 4 days of collection, similar to experiments one and two. Fecal bags 
were placed on the animals on day 6 and collection began in the morning on day 9. The tester steers were weighed on the day each trial started, and moved into a randomly assigned plot, and weighed again the day after the trial ended, and moved out of the plot. Tester steers were not allowed to remain in the plots any longer than necessary to prevent them from eating too much forage mass. The tester steers were given oats beginning on day 1 , and the fecal bags were placed on animals on day 6 , and subsequently changed twice daily on day 6 though 12 . Fecal samples were taken at the time bags were changed on day 8 through 12 . Fecal samples were taken at $5 \%$ of what was excreted for all three winter trials.

The tester steers were given $100 \mathrm{~g}$ of $\mathrm{YbCl}$ labeled oats, split equally into two feedings of $50 \mathrm{~g}$ each, beginning at 7:30 AM and 2:30 PM each day, during the pasture trial.

The second trial (January 27,2005 - February 7,2005$)$ was conducted on the tall fescue treatment plots, while the animals were being fed wrapped hay. Trial 2 used three of the fiver tester animals. One animal was assigned randomly to each of the three fescue replications, where they were fed wrapped hay. For two tester animals, collection began in the morning of day 9 and ended in the evening of day 12. The first collection for the third animal began in the evening of day 9 , and therefore ended on the morning of day 13 . Due to increasing day length, afternoon feeding and fecal collections started at 3:30 PM.

For the final trial (March 9, 2005- March 20, 2005), all five-tester animals were used on the six Orchardgrass and Native pasture replicates while the animals were receiving wrapped hay. One animal was collected only on days 9 
and 10 due to inability to maintain the collection bag on the steer with consequent possible loss of feces. Due to increasing day length, the second feeding and fecal collections began at 4:00 PM for the orchardgrass and native pasture hay trial. In order to prevent the tester animals from consuming any soyhulls, they were kept tied up until all the soyhulls were eaten.

\section{Sample Preparation and Analysis}

Bales were sampled with a hay probe prior to being fed. Hay and grass samples were kept refrigerated until freeze dried for 4 days. Grass samples were combined within each plot. Hay and baleage samples were combined within treatment. Hay, pasture, and fecal samples were analyzed as previously described for Experiment 1.

\section{$\underline{\text { Statistical Analysis }}$}

Experimental unit in Experiment 2 was animal. Intake data were analyzed using the GLM procedure of SAS. LSMeans were calculated for intake and animal performance data. Forage and replication were used as classes for intake determination and animal performance. Animal performance factors analyzed were beginning and end rump and rib fat, IMF, REA, and weight changes during each period. 


\section{Results and Discussion}

\section{Experiment 1: Predicting Intake in a Controlled Environment}

Average daily temperatures were recorded for each period and are reported in Figure 7. Average daily precipitation for all four trials was 0.24 inches. Average DM intake as a percentage of body weight for all four trials was $2.28 \%$.

Average start and end weights of steers for each trial are recorded in Table 1. Hay composition was determined and reported in Table 2. Contrary to what was expected, there was no difference seen in DMI as a percentage of body weight due to treatment (long vs short; 2.14 vs 2.02, respectively) in either experiment. There is evidence that shows an increase in intake when ground or pelleted diets are fed to ruminants (Van Soest, 1994). This is because pelleting, or grinding in this case, increases the surface area of the feed, making it more susceptible to breakdown and digestion. The feed is digested more quickly, passage rate is increased and retention time in the rumen is decreased, and overall intake increases. Retention time in the rumen is also influenced by initial particle size, rate of particle size reduction, particle density, and rate of digestion (Zinn and Ware, 2003). Typically, particles need to be smaller than $1 \mathrm{~mm}$ in order to pass out of the rumen, but 3 to $4 \mathrm{~mm}$ particle size has been reported in steers and dairy cows (Welch, 1986; Allen, 1996). In theory, steers should have consumed more of the fine chop hay because there would have been more surface area, passage rate would have increased, and bulk fill effects would have been decreased. Bulk fill or distension occurs due to a combination of the fibrous 
portion (mainly the NDF portion) of the plants and the physical limitation of the rumen. Forages high in the NDF portion of the plant, result in slower rates of digestion, causing the plant material to remain in the rumen longer, thus lowering intake. There was no difference in NDF intake as a percentage of body weight in either experiment between the two treatments (Table 3). A possible explanation for the lack of increase in intake for fine chopped hay was that the grinding process did not alter the NDF structure or content, therefore both groups of animals were subject to the same bulk fill effects despite the smaller particle size.

There was no difference $(P>0.10)$ in ash, NDF, ADF, ADL, or AIA intakes as a percentage of body weight due to treatment. There was a difference $(P<$ 0.05) in DM, AIA, NDF, ADF, and INDF intake as a percentage of body weight due to grass type (Timothy vs Orchardgrass). The difference in DMI was probably due to grass quality. The orchardgrass hay fed was higher quality than the Timothy hay, shown by NDF, ADF, ADL, protein, and DDM values (Table 2). Fisher (2002) reports that when limited protein is available, voluntary dry matter intake may decrease dramatically because of metabolic limitations to processing energy. Another reason for the reduced intake with the timothy hay was the low level of CP. In the rumen, microbes are turned over daily. Protein in the timothy hay was not enough for the microbes to reproduce, reducing fiber digestion. Van Saun (2005) suggests that microbes need $10.5-11 \%$ rumen degradable protein (RDP) to meet their nitrogen needs. Fu et al., (2001) reported that microbes showed their maximum efficiency with $8.7 \%$ RDP. There was no difference $(\mathrm{P}>$ 0.10 ) in ash or ADL intake as a percentage of body weight due to grass type. 
Indigestible NDF intake for Experiment 1 (Timothy hay; 0.8 as a percentage of body weight) was similar to previously reported values of 0.7- 0.8 as a percentage of body weight (Quinlan, 1994). Intake of INDF as a percentage of body weight in Experiment 1 was higher than the reported INDF intakes of 0.70.8 as a percentage of body weight.

In Experiment 1, recovery of AIA in the feces was consistently well over $100 \%$. This may be due to contamination of the feed with soil or other types of minerals. Van Keulen and Young (1977) reported that soil contamination was a problem with using AIA to predict intake. When the hay was harvested, there may have been soil on the grass. Dust may also have settled on the hay after it was chopped, during the storage period. Animals were seen licking the concrete feed bunks and wood used to construct the pens and consuming bedding. All of these activities would cause an increase in AIA excretion.

\section{Experiment 2: Winter Feeding: Predicting intake in a pasture setting and production of steers in winter forage systems}

Average daily temperatures are presented in Figure 8. Daily precipitation (rain and snow) data is presented in Figures 9, 10, and 11. Average start and finish weights of tester steers are reported for each trial in Table 4. Pasture and hay analysis is reported in Tables 5 and 6 . Average start and end weights and average daily gain (ADG) for steers are reported in Table 7 .

There were no differences in beginning body weight, rump fat, rib fat, intramusclular fat (IMF), or rib eye area (REA). Because animals were randomly assigned to treatment and replication, this was expected. There were no 
differences in weight gain during the first two weigh periods. There were differences seen at the end of the third weight period. These differences were carried over into differences in the overall ADG of steers for the winter grazing period (Table 8). The differences in weight gains during the different periods of grazing may be related to the amount of available forage and forage quality. The quality and possibly quantity of stockpiled orchardgrass or native pastures may not be adequate enough to provide steers with the energy they need to sustain them through the winter. From previous research, it is known that tall fescue is well adapted for stockpiling and will retain its quality into the fall and winter (Baker et al., 1988; Allen et al., 2000; Barnes et al., 2003). Baker et al. (1988) reported that during the winter period, the quality of tall fescue was higher than orchardgrass quality. When looking at the performance of steers throughout the winter period for this experiment, using ADG as a measurement, animals on the tall fescue treatment attained higher gains, indicating there may have been a difference between the tall fescue and orchardgrass treatments, in pasture and grass quality. Previous research has also stated that orchardgrass can provide adequate nutrients to sustain animals into late fall, and after this quality declines (Baker et al., 1988). Judging by weight changes in these animals, there were no significant differences in weight changes until 6 weeks into the experiment (the middle of January). After this time, both orchardgrass treatments had the lowest gains. This may indicate a larger drop in the quality and quantity of forage available to the animals, compared to the tall fescue and native pasture treatments. During March, animals on the tall fescue plots were observed 
grazing new grass growth. Attempts to take grass samples were made, but there was not enough growth to sample from. This additional grass growth may explain why animals on the fescue plots gained more than animals on the other treatments. This new growth would have been higher quality than the wrapped hay, giving the animals an advantage, in terms of energy intake, over other groups of animals.

Once animals were fed wrapped hay (beginning on 2/15/05), theoretically, all animals should have gained at the same rate, as the hay was all harvested at the same time, from the same fields. One possible explanation for this discrepancy is the location of the plots on the farm. The plots were located at different areas on the farm (Figure12), and therefore, were subject to different amounts of cover from the elements. The native treatment was located adjacent to a road with virtually no tree protection or terrain protection. The two orchardgrass treatments were located at the top of a hill with no tree or terrain protection. The tall fescue plots were surrounded on two sides with fairly heavy tree cover, and on a third side by elevated terrain. The animals grazing the tall fescue plots, which appeared to have the most protection from the elements, gained the most.

Following the third weigh period, animals on the Native, OGHaylage, and OGHay treatments failed to gain the predicted $0.5 \mathrm{~kg} / \mathrm{head} / \mathrm{day}$, so animals were supplements with soyhulls (Table 9).

There was a tendency $(P<0.10)$ for end rib fat to be lower in the OGHay treatment due to forage type (Table 10). There were no differences in end rump 
fat, IMF, or REA ( $P$ > 0.10). Animals in the OGHaylage, Native, and Fescue groups may have been slightly more physiologically mature than the OGHay group, and at an age where they were beginning to deposit more fat. This group of animals was located at the Livestock Farm in Morgantown and subject to different management, this may have been a factor in reduced gains. The grazing period lasted about 100 days, in this time period and at the age of the animals, they should not be depositing much fat in the areas that were ultrasounded (rump or IMF). Kidney, pelvic, and heart fat is deposited first, followed by subcutaneous, and finally inter- and intramucular fat (Boggs et al., 1993).

There were no differences in DM, ash, NDF, or ADF intake as a percentage of body weight between trials or forages. There should have been no differences in any of these factors during the hay-feeding period, due to all hay being harvested from the same fields at the same time. Upon analysis (Table 5) pasture samples appeared to be similar in quality, thus there were no differences in the intakes of measured entities. There was a difference $(P<0.05)$ in ADL and INDF intake as a percentage of body weight between the three trials (Table 11). Indigestible NDF intake was much lower during the Fescue Hay trial compared to the orchardgrass and native hay trials. One explanation for this is that animals in the fescue plots had access to higher quality bales than the other treatments. Indigestible NDF intakes as a percentage of body weight for the orchardgrass and native hay trials were also similar to the reported values of 0.70.8 from Quinlan (1994). When looking at INDF intake, in two different tall fescue 
replications, a decrease was observed in INDF intake while the animals were grazing. For replication 1, Day 11 corresponds with the day animals were allowed into the next section of the field for grazing (Figure 13). Forage was more available and was of higher quality in the new section of field, thus INDF intake decreased. Animals grazed down all available forage before being allowed into the next section of the field, so any remaining forage would be poor quality. This was also seen with animals in replication 3 (Figure 14). Day 10 corresponds with a day the next section of field was opened up for grazing. Forage consumed was higher quality, thus lowering INDF intake.

Consistent with results of Experiment 1, fecal AIA recovery, for all three trials in Experiment 2, was well over 100\%. In both situations, confined animals and grazing animals, there is too much chance on contamination by minerals (soil, salt blocks, etc.) to use this response for predicting intake.

Similar INDF values were reported for Experiment 1 and the orchardgrass and native hay trial in Experiment 2. Indigestible NDF intake may be more reliable and predictable when using hay, rather than animals on pasture. The idea of INDF being more predicable in a confined situation may be due in part to animals in Experiment 1 being confined and fed hay ad libitum. Therefore, there was no need for competition between the animals, and no need for animals to wander around to find forage. In the pasture trials during Experiment 2, there may have been competition between animals for higher quality forage. One possible reason for the reduced intake when animals were fed hay during Experiment 2 was there was not enough available forage for the animals. This 
may be due, in part, to animals wasting available hay. From visual observation, a large amount of hay was trampled and soiled by the animals. One way to avoid this problem is to feed hay in a feeder, rather than spreading it on the ground. There was no consistency in INDF intake between the treatments in the pasture trial. This may be due to variations in plant quality between species.

A limitation of Experiment 2 is that the diet consumed by the tester steers may not have been indicative of what was consumed by the other, younger grazing animals in the plot. Because the tester animals were older and larger than the other four steers, they were the dominant animals in the group, thus possibly eliminating any competition with other animals for the available forage. Animals on the tall fescue treatment were the only ones to achieve gains close to the projected $0.5 \mathrm{~kg} / \mathrm{head} / \mathrm{d}$. Thus, it may be necessary to reevaluate the other winter forage system tested.

One of the characteristics necessary for a marker is consistency. None of these markers tested showed any consistency across grass species. Experiment 1 showed consistency in marker intake within grass species, despite processing treatment. Acid insoluble ash showed the least variability in intake in Experiment 1. However, seen here and in previous experiments using AIA as an intake marker, recovery was well over $100 \%$ showing that there may be some problem with how it is determined. 


\section{Tables and Figures}

Figure 1. Division of forage organic matter using detergents

Fraction Components

Cell contents (soluble in neutral detergent)

Lipids

Sugars, Organic acids and Water Soluble matter

Pectin

Starch

Non- protein nitrogenous

Compounds

Soluble proteins

Cell wall constituents (fiber insoluble In neutral detergent)

1- soluble in acid detergent

Fiber bound protein

Hemicellulose

2- Acid detergent fiber

Cellulose

Lignin

Lignified nitrogenous compounds 
Figure 2. Conceptual diagram of intake regulation based on psychogenic (1), physiological (2), and physical (3) theories of intake. Solid lines are nutrient flows, and dashed lines are information or stimuli flows. The $X$ indicates a

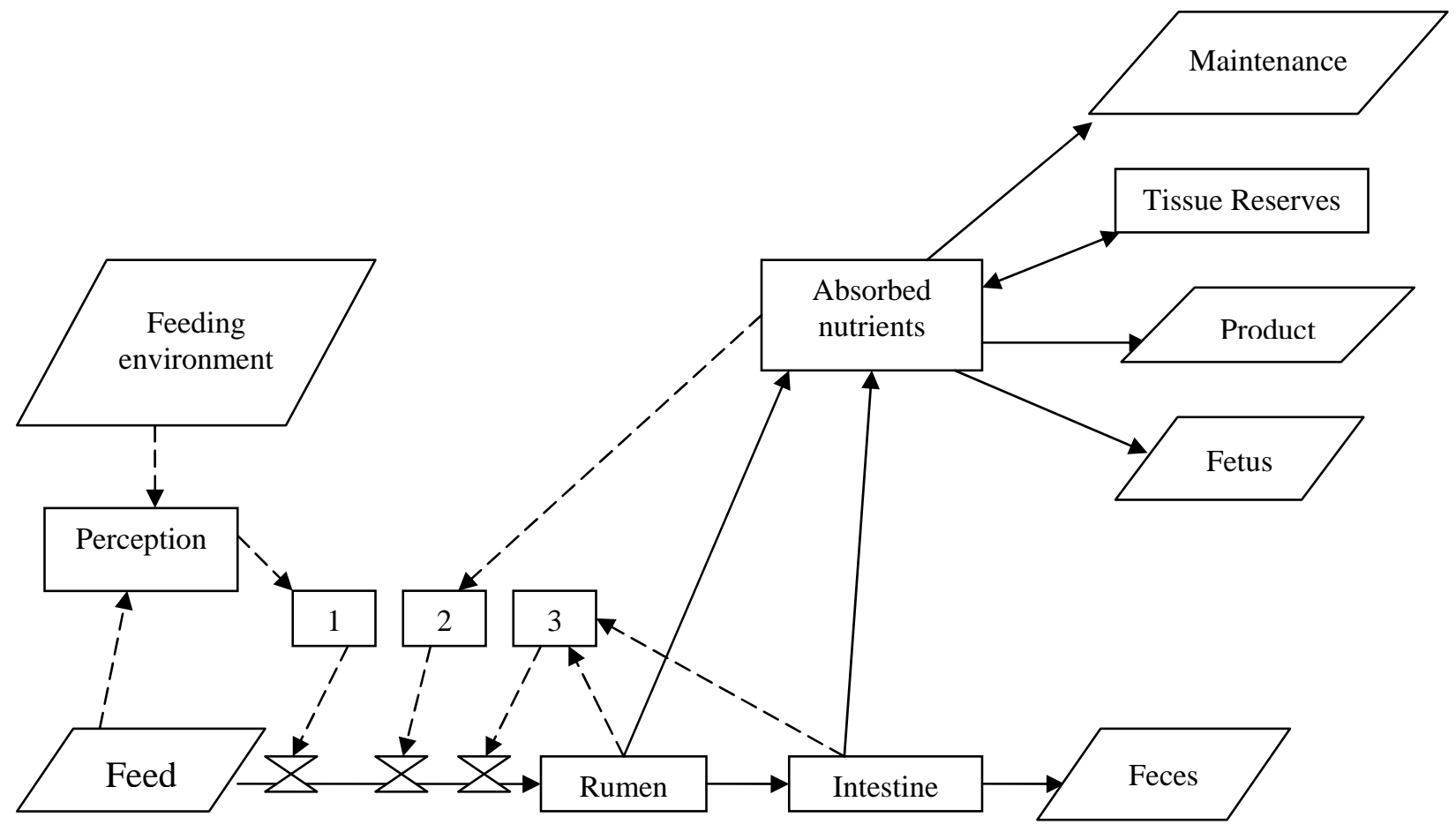


Figure 3. Animal Characteristics affecting intake

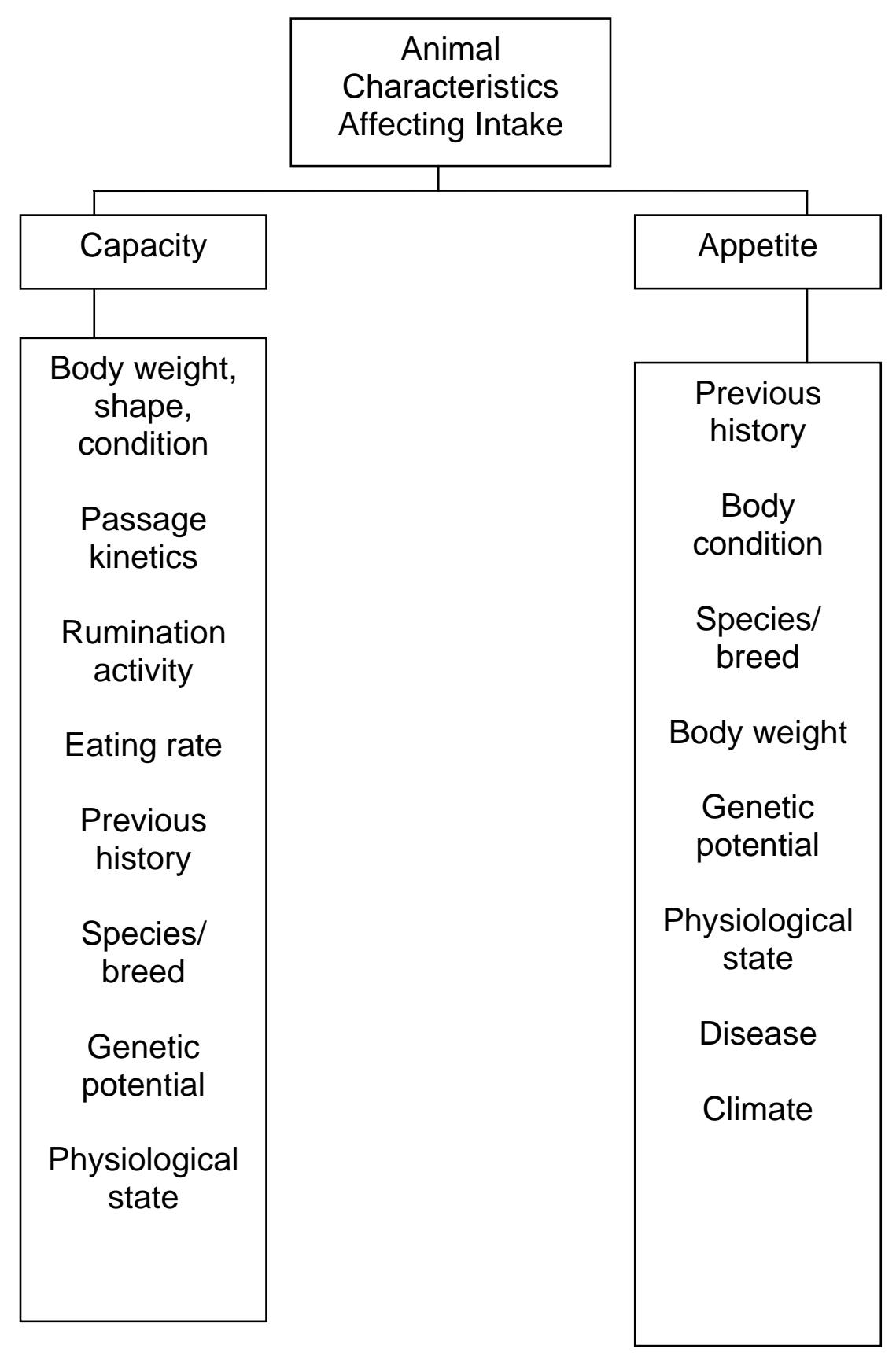


Figure 4. Feed characteristics affecting intake

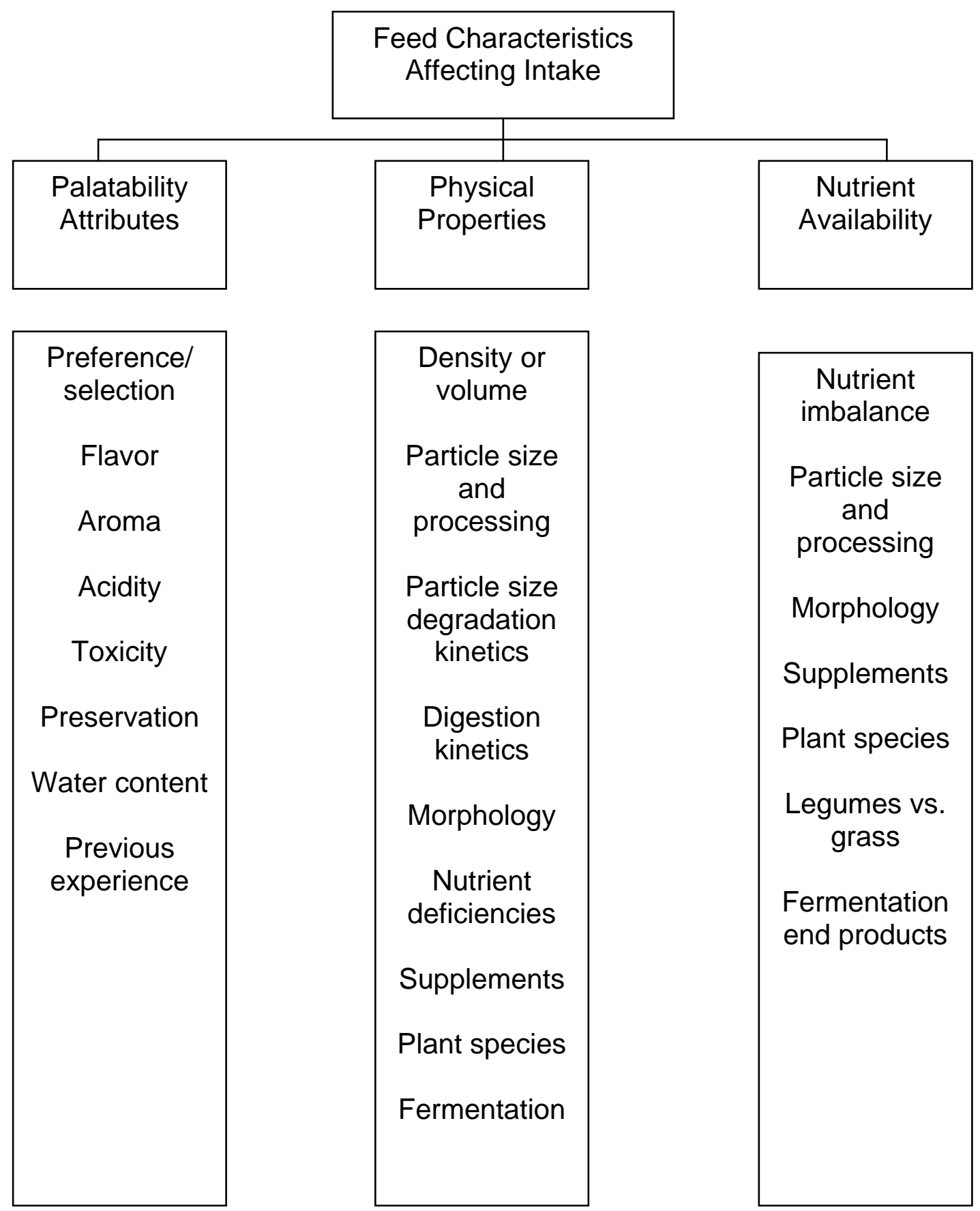


Figure 5. Management factors affecting intake

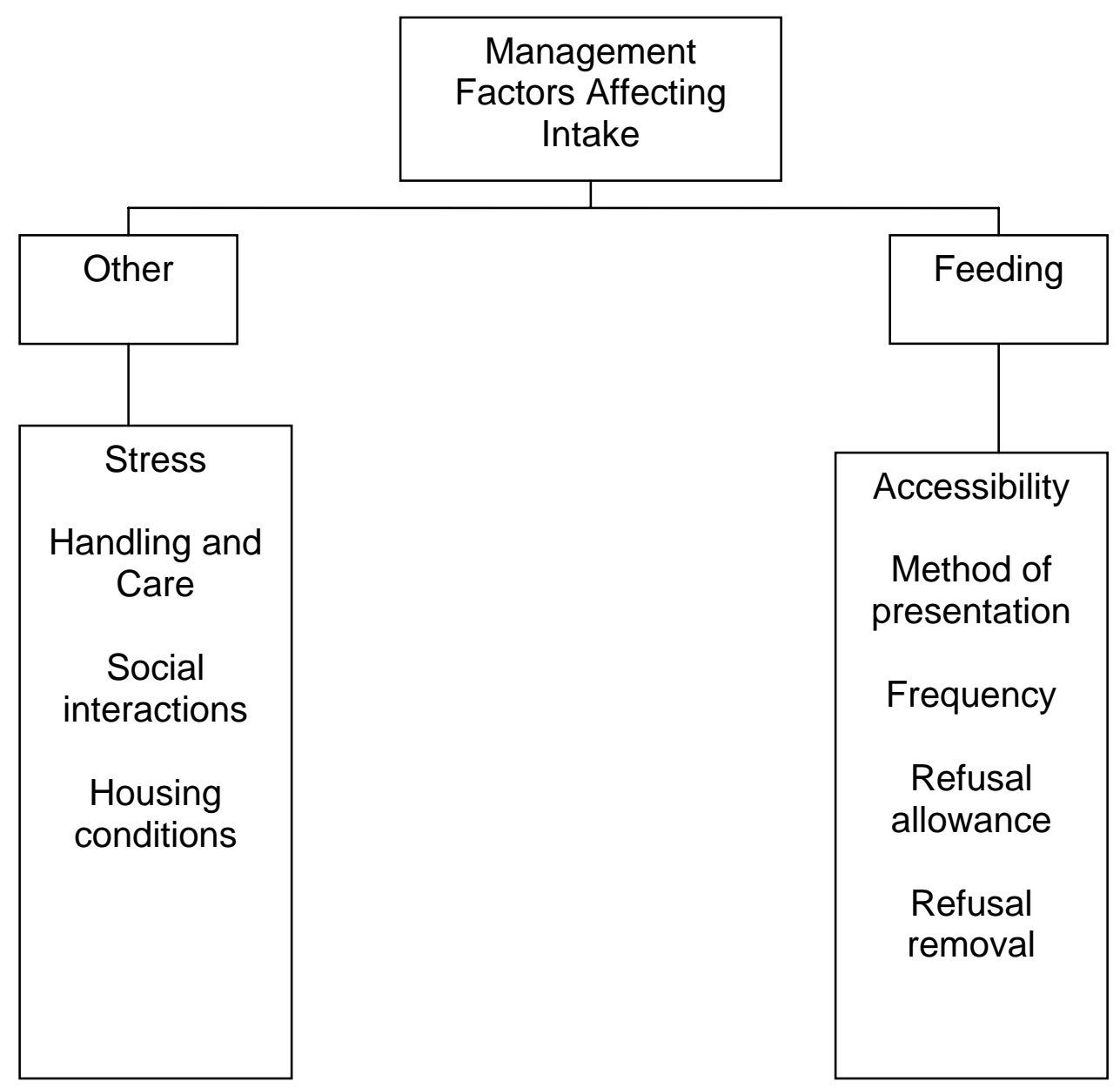


Figure 6. Basic Experimental Protocol

Day 1: weigh animals, weigh feed

Day 2: weigh feed and orts

Day 3: weigh feed and orts

Day 4: weigh feed and orts

Day 5: weigh feed and orts

Day 6: weigh feed and orts, fecal bags on

Day 7: weigh feed and orts, feed given sampled

Day 8: weigh feed and orts, feed given sampled, and orts sampled

Day 9: weigh feed and orts, feed given sampled, orts sampled, fecal sampling starts PM

Day 10: weigh feed and orts, feed given and orts sampled, fecal samples taken Day 11: weigh feed and orts, feed given and orts sampled, fecal samples taken Day 12: weigh feed and orts, feed given and orts sampled, fecal samples taken Day $13 / 1^{\mathrm{a}}$ : weigh animals, fecal sample AM, fecal bags off, weight and samples of orts taken, Orchardgrass Trial 2 began on the same day that Orchardgrass Trial 1 ended

${ }^{a}$ During Period 2, Trial 2 began on the same day that Trial 1 ended. 
Figure 7. Average daily temperature (Experiment 1). Data is presented as the mean of the daily high and low.

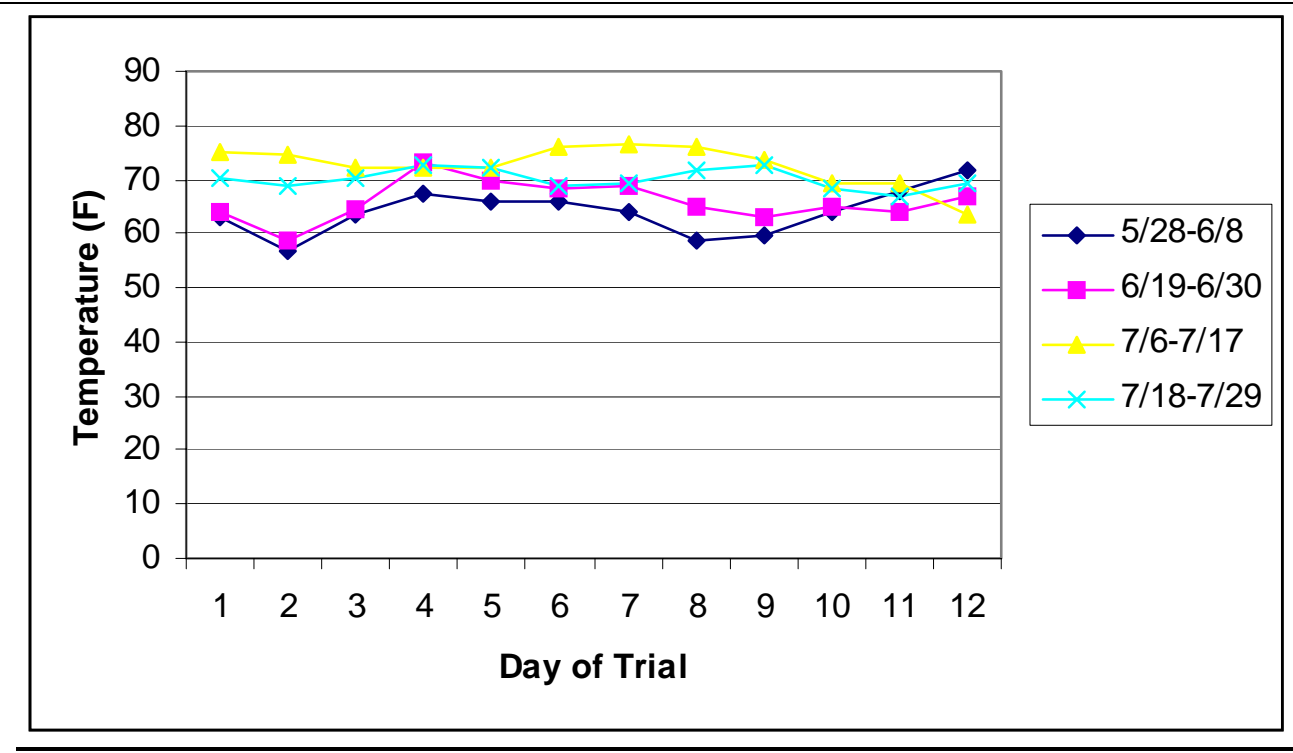

Figure 8. Average daily temperature (Experiment 2). Data is presented as the mean of the high and low daily temperature.

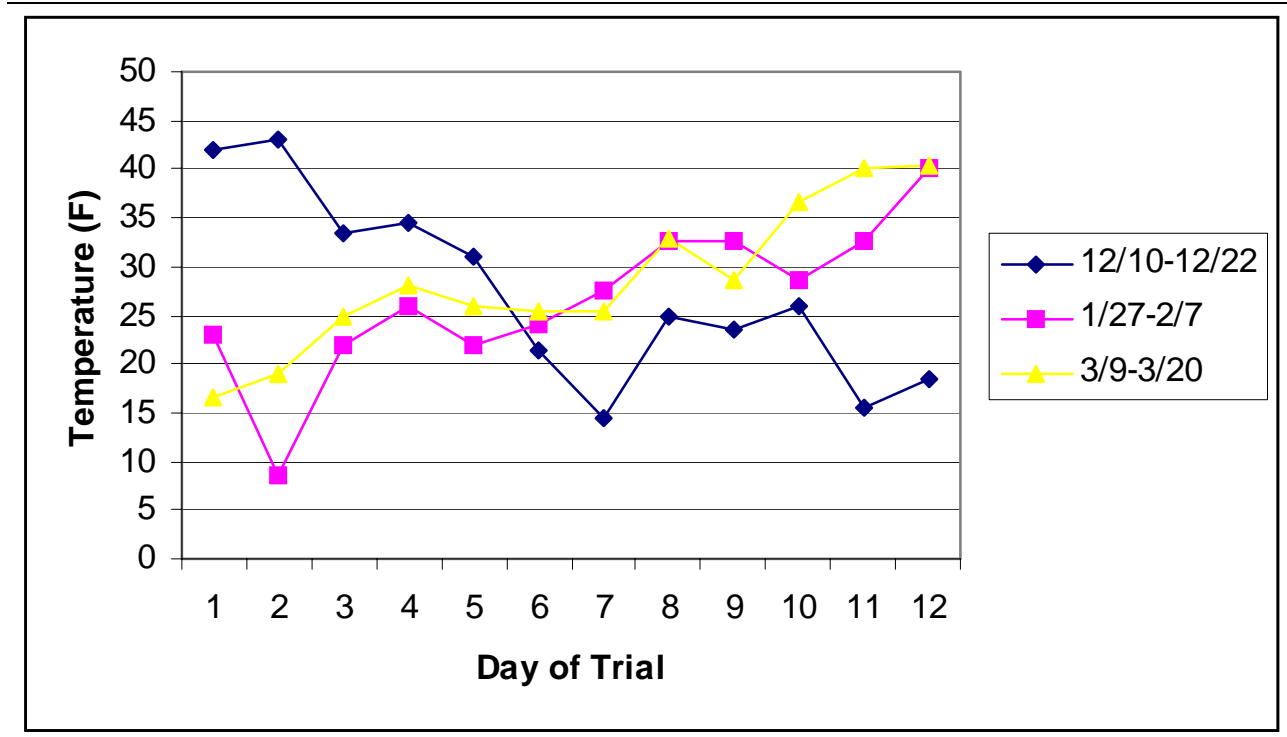


Figure 9. Pasture Trial Daily Precipitation (rain and snow; reported in inches).

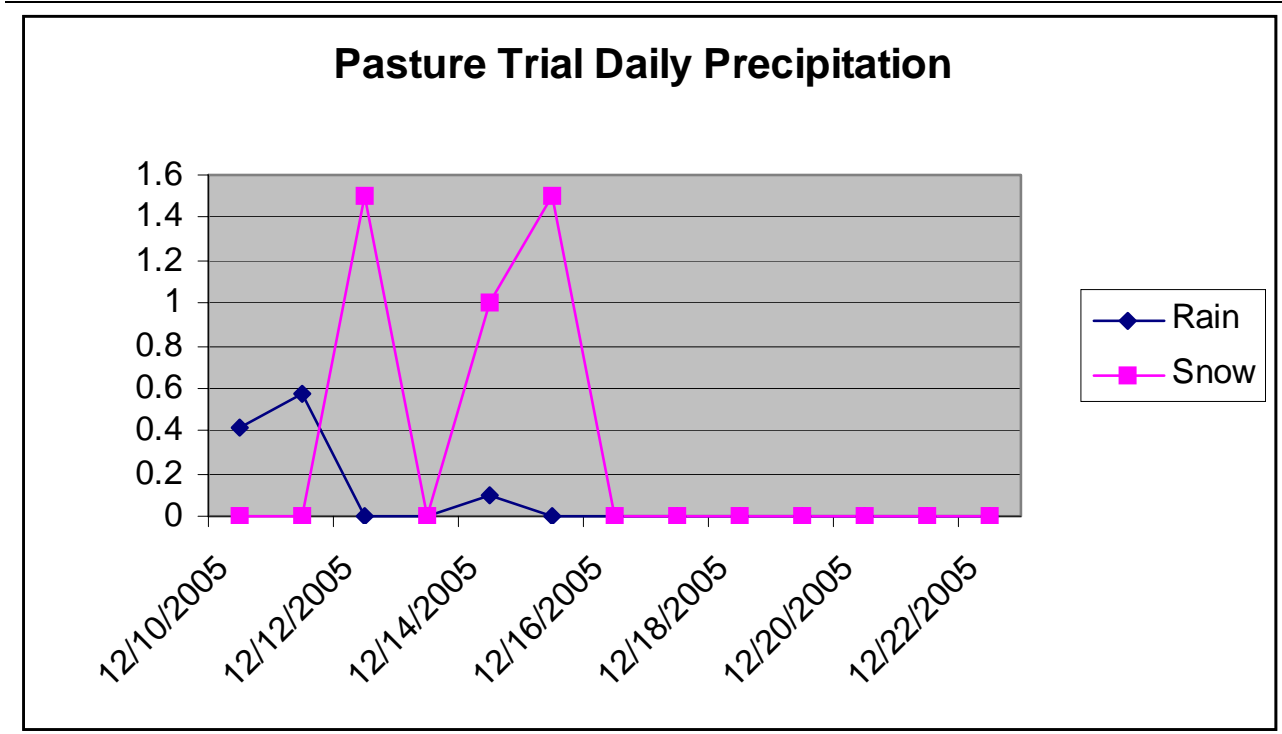

Figure 10. Fescue Hay Trial Daily Precipitation (rain and snow; reported in inches).

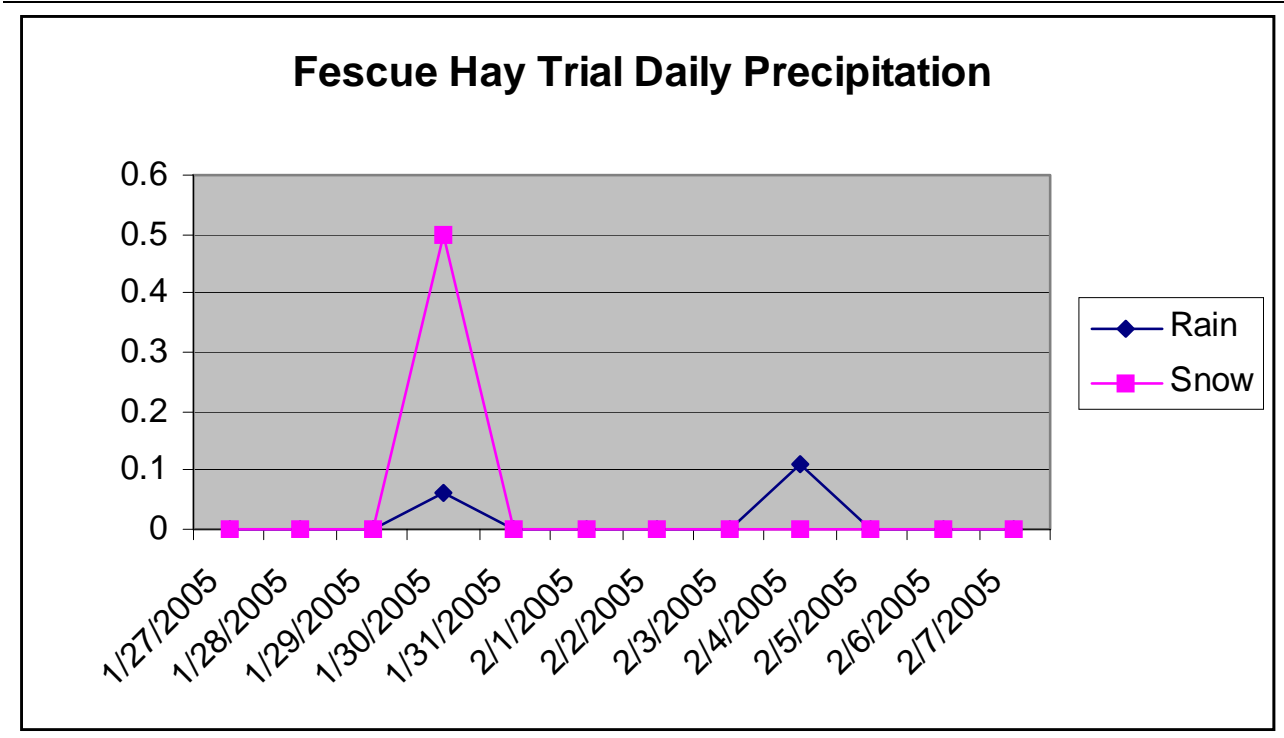


Figure 11. OG and Native Hay Trial Daily Precipitation (rain and snow; reported in inches).

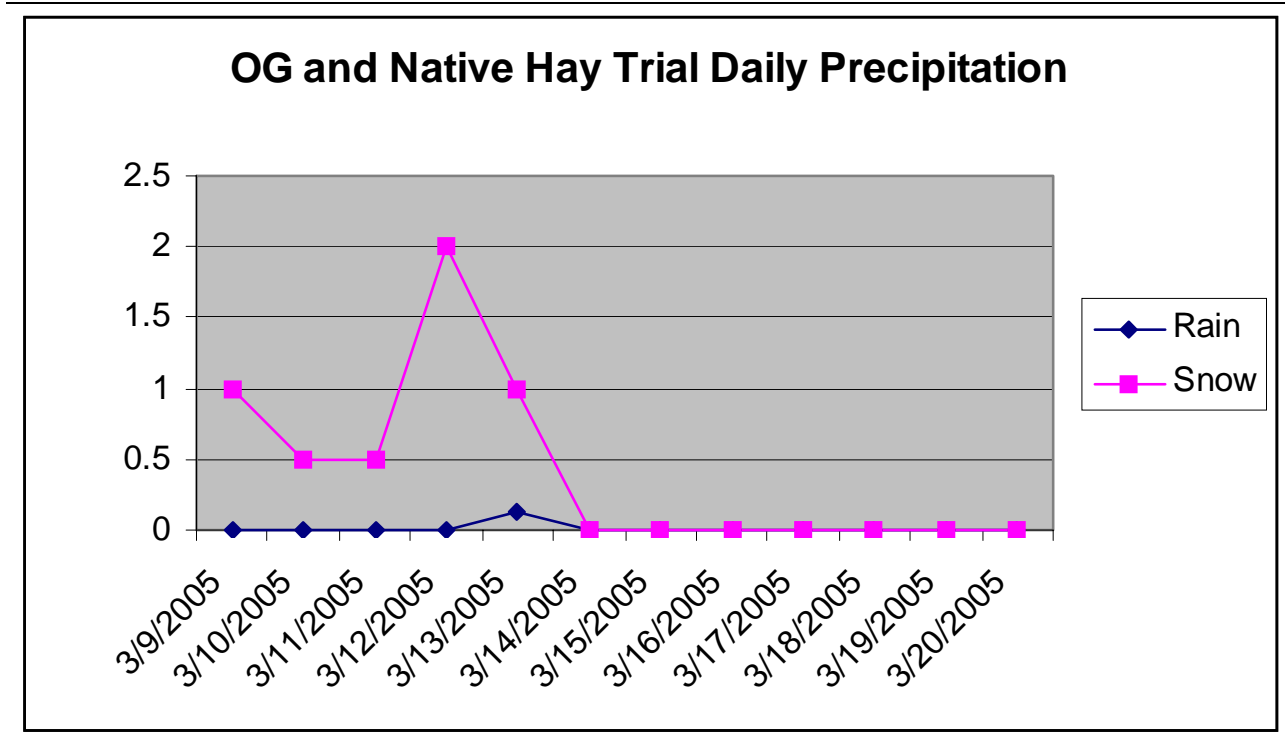


Figure 12. Location of winter grazing treatments at Reedsville Experimental Farm, Preston County, WV

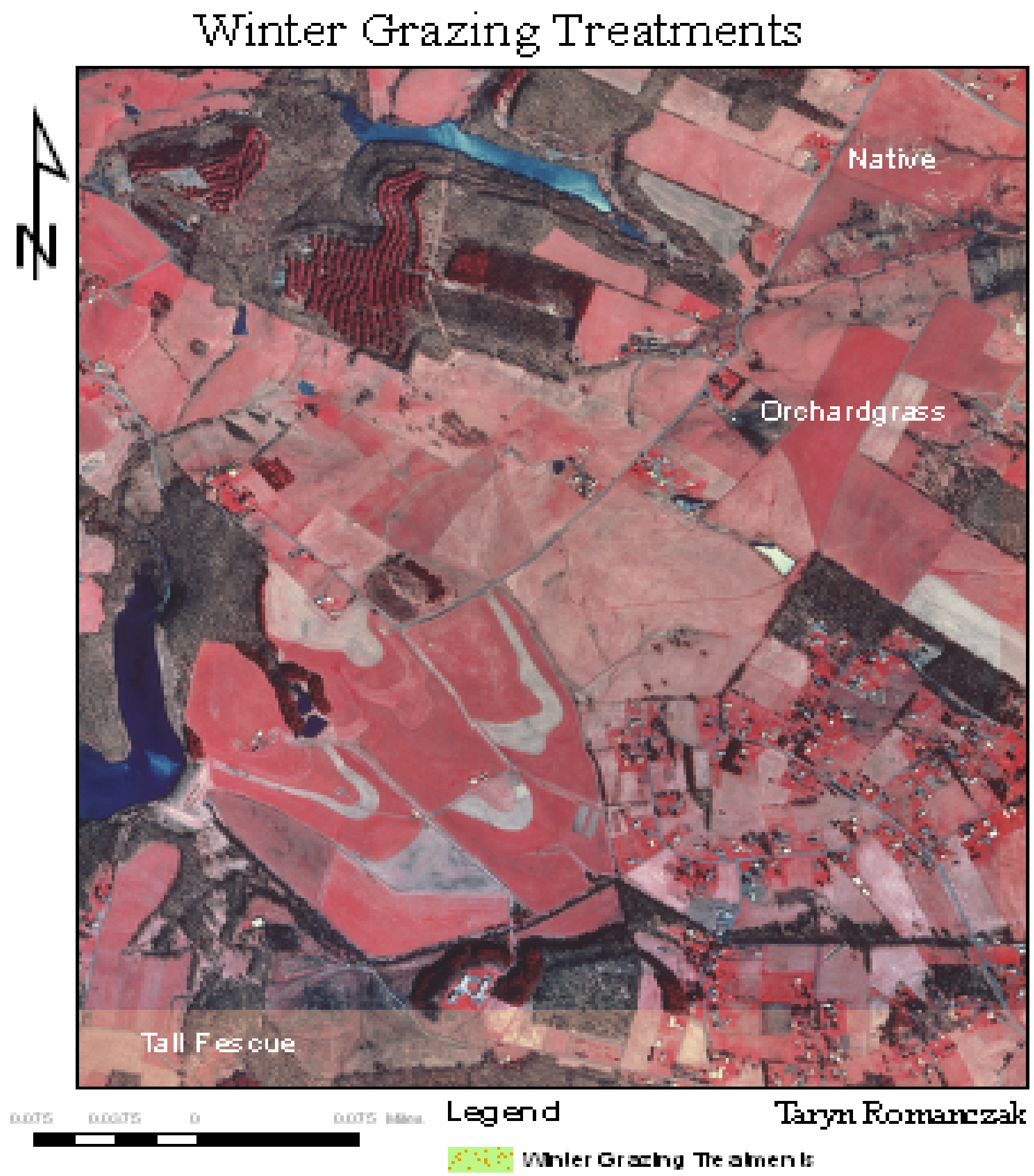


Figure 12. Tall Fescue Treatment, replication 1, INDF intake as a percentage of body weight

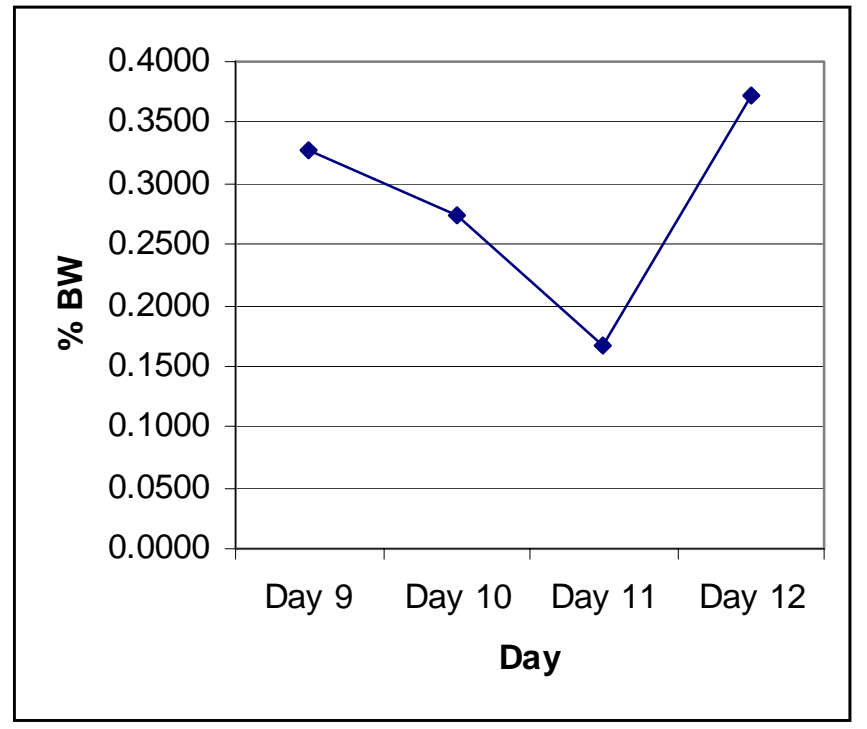

Figure 13. Tall Fescue Treatment, replication 3, INDF intake as a percentage of body weight

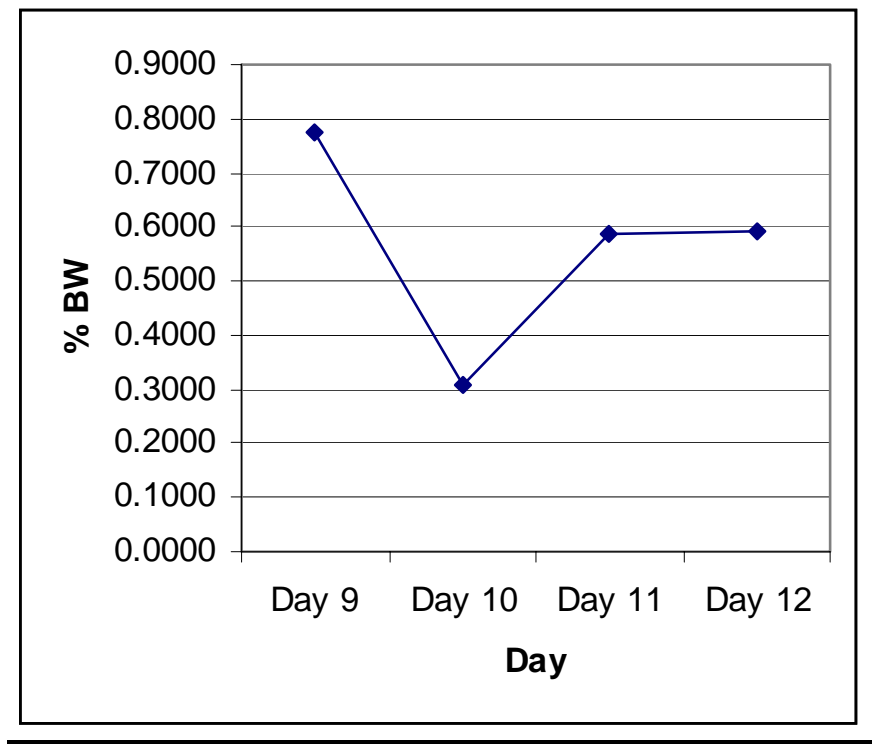


Table 1. Average Body Weight (kgs) of steers at Beginning and End of each trial

\begin{tabular}{llll}
\hline Trial & Period & Beginning Weight & End Weight \\
\hline 1 & 1 & 310.7 & 316.7 \\
1 & 2 & 323.8 & 317.6 \\
2 & 1 & 321.2 & 318.8 \\
2 & 2 & 318.8 & 323.0 \\
\hline
\end{tabular}

Table 2. Hay Analysis Timothy Hay and Orchardgrass hay

\begin{tabular}{lll}
\hline \hline & Timothy & Orchardgrass \\
\hline DM, \% & 90.90 & 89.65 \\
Ash, \% & 3.50 & 4.15 \\
NDF, \% & 75.45 & 67.95 \\
ADF, \% & 44.80 & 40.55 \\
ADL,\% & 14.9 & 5.00 \\
CP, \% & 4.20 & 7.95 \\
INDF, \% & 33.35 & 28.50 \\
DDM, \% & 54.01 & 57.31 \\
\hline
\end{tabular}

Table 3. DM, NDF, ADF, INDF, and AIA Intakes as a percentage of body weight ${ }^{\mathrm{a}}$

\begin{tabular}{cccccc}
\hline \hline Hay Type & $D M$ & NDF & $A D F$ & INDF & AIA \\
\hline Timothy & 1.75 & 1.32 & 0.78 & 0.82 & 0.01 \\
Coarse & 1.83 & 1.38 & 0.80 & 0.78 & 0.01 \\
Fine & 1.67 & 1.26 & 0.76 & 0.85 & 0.01 \\
Orchardgrass & 2.41 & 1.64 & 0.95 & 1.02 & 0.02 \\
Coarse & 2.51 & 1.66 & 0.94 & 1.04 & 0.02 \\
Fine & 2.54 & 1.61 & 0.96 & 1.01 & 0.02 \\
\hline
\end{tabular}

${ }^{a}$ Numbers in italics describe main effects and differ $(P<0.05)$. There was no difference in DM, NDF, ADF, INDF, or AIA intakes as a percentage of body weight due to treatment (coarse or fine). 
Table 4. Average body weight (kgs) of tester steers during each trial

\begin{tabular}{llll}
\hline & \multicolumn{3}{c}{ Trial } \\
& Pasture & Fescue hay & OG/Native Hay \\
\hline Start & 406.3 & 420.0 & 426.0 \\
Finish & 402.2 & 409.7 & 435.8 \\
\hline
\end{tabular}

Table 5. Pasture Trial Grass analysis

\begin{tabular}{llll}
\hline \hline & & Pasture & \\
& Fescue & Native & Orchardgrass \\
\hline Ash,\% $\%$ & 9.15 & 7.90 & 6.70 \\
NDF,\% & 62.20 & 54.0 & 68.50 \\
ADF\% & 35.15 & 28.40 & 39.05 \\
ADL,\% & 6.05 & 2.00 & 2.40 \\
CP,\% & 9.85 & 16.00 & 9.30 \\
INDF,\% & 24.41 & 18.49 & 28.99 \\
DDM,\% & 70.51 & 66.36 & 77.10 \\
\hline
\end{tabular}

Table 6. Analysis of hay fed on the Fescue, Orchardgrass, and Native treatment

\begin{tabular}{lllll}
\multicolumn{5}{c}{ plots } \\
\hline \hline & Fescue & OGHaylage & Native & OGHay \\
\hline Ash,\% & 5.70 & 15.50 & 9.90 & 15.45 \\
NDF,\% & 68.60 & 59.60 & 68.10 & 59.56 \\
ADF,\% $\%$ & 38.80 & 32.30 & 44.90 & 32.31 \\
ADL,\% & 5.40 & 14.00 & 14.80 & 14.03 \\
CP,\% $\%$ & 11.10 & 10.90 & 12.50 & 10.86 \\
INDF,\% & 46.16 & 46.84 & 45.64 & 46.83 \\
DDM,\% & 69.70 & 79.36 & 68.51 & 69.70 \\
\hline
\end{tabular}


Table 7. Winter Pasture Grazing: Steer start and end weights and ADG (kgs)

\begin{tabular}{llll}
\hline Treatment & $\begin{array}{l}\text { Start weight } \\
\text { Average }\end{array}$ & $\begin{array}{l}\text { End Weight } \\
\text { Average }\end{array}$ & ADG \\
\hline Native & 246.3 & 285.3 & .32 \\
OGHaylage & 255.2 & 289.3 & .28 \\
OGHay & 246.5 & 273.4 & .22 \\
Fescue & 242.0 & 295.4 & .44 \\
\hline
\end{tabular}

Table 8. Weight gain ADG (kgs) of steers: Effects due to forage type Dates

\begin{tabular}{cccccc} 
& \multicolumn{5}{c}{ Dates } \\
Treatment & $12 / 2-1 / 3$ & $1 / 3-1 / 31$ & $1 / 31-3 / 10^{1}$ & $3 / 10-4 / 4^{1}$ & Overall $^{1}$ \\
\hline Fescue $^{\star}$ & 17.54 & 9.76 & 20.60 & $3.98^{\mathrm{c}}$ & 52.68 \\
ADG & 0.56 & 0.35 & 0.16 & $0.16^{\mathrm{c}}$ & 0.44 \\
OGHay $^{*}$ & 21.25 & 0.23 & $-8.71^{\mathrm{c}}$ & $14.17^{\mathrm{ab}}$ & $26.93^{\mathrm{c}}$ \\
ADG & 0.69 & 0.01 & $-0.24^{\mathrm{c}}$ & $0.11^{\mathrm{ab}}$ & $0.22^{\mathrm{c}}$ \\
OGHaylage* $^{*}$ & 16.90 & 4.58 & $3.52^{\mathrm{b}}$ & $8.64^{\mathrm{abc}}$ & $34.09^{\mathrm{bc}}$ \\
ADG & 0.56 & 0.16 & $0.09^{\mathrm{b}}$ & $0.35^{\mathrm{abc}}$ & $0.28^{\mathrm{bc}}$ \\
Native $^{*}$ & 23.15 & 4.05 & $-3.07^{\mathrm{bc}}$ & $14.85^{\mathrm{a}}$ & $38.98^{\mathrm{b}}$ \\
ADG & 0.75 & 0.15 & $-0.08^{\mathrm{bc}}$ & $0.60^{\mathrm{a}}$ & $0.32^{\mathrm{b}}$ \\
\hline
\end{tabular}

${ }^{1}$ Means within the column with different superscripts differ $(P<0.05)$ 
Table 9. Level of soyhulls (kgs) fed when ADG fell below the expected levels, after the third weigh period

\begin{tabular}{lll}
\hline Treatment & Rep & Kgs. Of Soyhulls given \\
\hline Native & 1 & 4.5 \\
& 2 & 4.4 \\
OGHaylage & 3 & 4.0 \\
& 1 & 4.1 \\
OGHay & 2 & 4.7 \\
& 3 & 4.6 \\
& 1 & 4.0 \\
& 2 & 4.5 \\
\hline
\end{tabular}

Table 10. Beginning and end rump fat (in), rib fat (in), REA (in ${ }^{2}$ ), and IMF (\%)

\begin{tabular}{lllllllll}
\hline \hline & \multicolumn{3}{c}{ Start } & \multicolumn{4}{c}{ End } \\
\hline Treatment & Rump & Rib & REA & IMF & Rump & Rib & REA & IMF \\
\hline Native & 0.10 & 0.10 & 6.30 & 3.75 & 0.10 & 0.08 & 6.17 & 2.88 \\
OGHaylage & 0.11 & 0.11 & 6.45 & 3.89 & 0.11 & 0.08 & 6.90 & 3.94 \\
OGHay & 0.10 & 0.11 & 6.63 & 3.64 & 0.10 & $0.07^{\mathrm{a}}$ & 5.76 & 2.86 \\
Fescue & 0.12 & 0.12 & 6.86 & 3.82 & 0.13 & 0.09 & 6.76 & 3.37
\end{tabular}

$\overline{\mathrm{a}, \mathrm{b}}$ Means within a column with difference superscripts differ $(\mathrm{P}<0.1)$ 
Table 11. INDF and ADL Intake as a percentage of body weight

\begin{tabular}{lll}
\hline Treatment & INDF & ADL \\
\hline OGHaylage & 0.64 & 0.05 \\
Native & 0.32 & 0.03 \\
Fescue & 0.42 & 0.10 \\
Pasture Trial* & 0.46 & 0.06 \\
Fescue Hay & 0.45 & 0.09 \\
Fescue Hay* & 0.45 & 0.09 \\
OG Hay & 0.69 & 0.19 \\
Native Hay & 0.61 & 0.20 \\
Hay Trial* & 0.65 & 0.20 \\
\hline *Trial Averages. Pasture trial is average of OGHaylage, Native, and Fescue.
\end{tabular}
Fescue hay is the values from Fescue Hay alone, and Hay trial is the average of OG Hay and Native Hay.

There was a significant difference $(P<0.05)$ for a difference in INDF and ADF intake between trials. 


\section{Vl. Works Cited}

Allen, M.S. 1996. Physical constraints on voluntary intake of forages by ruminants. J. Anim. Sci. 74: 3036-3075.

Allen, V.G., J.P. Fontenot, and D.R. Notter. 1992. Forage systems for beef production from conception to slaughter II. Stocker systems. J. Anim. Sci. 70: 588- 596.

Allen, V.G., J.P. Fontenot, D.R. Notter, and R.C. Hammes, Jr. 1992. Forage systems for beef production from conception to slaughter: I. Cow-calf production. J. Anim. Sci. 70: 576-587.

Allen, V.G., J.P. Fontenot, R.F. Kelly, and D.R. Notter. 1996. Forage systems for beef production from conception to slaughter III. Finishing systems. J. Anim. Sci. 74: 625-638

Allen, V.G., J.P. Fontenot, and R.A. Brock. 2000. Forages systems for production of stocker steers in the upper south. J. Anim. Sci. 78: 1973-1982.

Appeddu, L.A. and M.A. Brown. 2002. Use of intake and digestibility markers in stockers grazing wheat. United States Department of Agriculture/Agriculture Research Service. Progress Reports from the Grazinglands Research Laboratory, El Reno, OK.

ArcMap 9.1. 2004. ESRI. Redlands, CA.

Bagley, C.P., J.P. Fontenot, R.E. Blaser, and K.E. Webb Jr. 1983. Nutritional value and voluntary intake of tall fescue (Festuca arundinacea Schreb.) fed to sheep. J. Anim. Sci. 57: 1383-1390.

Baile, C.A. 1975. Control of feed intake in ruminants. In: Digestion and metabolism in the ruminant. P 333.

Baile, C.A., and Forbes, J.M. 1974. Control of feed intake and regulation of energy balance in ruminants. Physiol. Rev. 54: 160-213.

Baker, M.J., E.C. Prigge, and W.B. Bryan. 1988. Herbage production from hay fields grazed by cattle in fall and spring. $\mathrm{J}$ of Production Agriculture. 1: $275-279$

Balasko, J.A. 1977. Effects of N, P, and K fertilization on yield and quality of tall fescue forages in winter. Agron. J. 69: 425-428.

Barnes, R.F., C.J. Nelson, M. Collins, and K.J. Moore. 2003. Forages: An Introduction to Grassland Agriculture, Volume 1. lowa State Press, Ames. 
Barnhart, S.K. 1998. Stockpiled forages: A way to extend the grazing season. lowa State University Extension Service. Accessed August 5, 2005. www.extension.iastate.edu.

Baron, V.S, A.C. Dick, M. Bjorge, and G. Lastiwka. 2004. Stockpiling potential of perennial forage species adapted to Canadian western prairie parkland. Agron. J. 96: 1545-1552.

Bassford, M. 2000. Smooth Bromegrass. Accessed July 8, 2005. www.muextension.missouri.edu.

Boggs, D.L., R.A. Merkel, and M.E. Doumit. Growth, development, and fattening of meat animals. In: Livestock and Carcasses: An integrated approach to evaluation, grading, and selection. Kendall/Hunt Publishing Company. lowa.

Brown, L.R. 2001. World grain harvest falling short by 54 million tons. Earth Policy Institute. November.

Bryan, W.B. and T.A. Mills. 1988. Seasonality of pasture growth in West Virginia. Proceedings of the $12^{\text {th }}$ General Meeting of the European Grassland Federation. Dublin, Ireland.

Bryan, W.B., T.A. Mills, and F.X. Posica. 1987. Effects of grazing management and soil amendment on hill land pasture botanical composition. Applied Agricultural Research. 1: 297-302.

Burns, J.C., K.R. Pond, and D.S. Fisher. 1994. Measurement of forage intake. In: G.C. Fahey Jr., M. Collins, D.R. Mertens, and L.E. Moser (Ed) Forage Quality, Evaluation, and Utilization. P 494. ASA-CSSA-SSSA, Madison, WI.

Cole, N.A. 1991. Effects of animal-to-animal exchange of ruminal contents on Feed intake and ruminal characteristics of fed and fasted lambs. J. Anim. Sci. 69: 1795-1803.

Coombs, D.F., C.P.Bagley, G.M. Hill, J.W. Knox, A.F. Loyacano, W.M. Oliver, W.E. Wyatt, D.C. Huffman, K.W. McMillin, T.D. Bidner, and A.M. Saxton. 1990. Year-round production of beef using maximum levels of forage. II. Finishing phase. Applied Agricultural Research. 5: 315-320.

Delfino, J.G. and G.W. Mathison. 1991. Effects of cold environment and intake level on the energetic efficiency of feedlot steers. J. Anim. Sci. 69: 45774587. 
Dove H. and R.W. Mayes. 1991. The use of plant wax alkanes as marker substances in studies of the nutrition of herbivores: A review. Australian Journal of Agricultural Research. 42: 912-952.

Dove, H. and R.W. Mayes. 1996. Plant wax components: A new approach to estimating intake and diet composition in herbivores.J. Nutr. 126:13-26.

D'Souza, G.E., E.W. Maxwell, W.B. Bryan, and E.C. Prigge. 1990. Economic impacts of extended grazing systems. American Journal of Alternative Agriculture. 5:120-125.

Duncan, A.J., R.W. Mayes, C.S. Lamo, S.A. Young, and I. Castillo. 1999. The use of naturally occurring and artificially applied $n$ - alkanes as markers for estimation of short- term diet composition and intake in sheep. J. of Agricultural Science. 132: 233-246.

Dulphy, J.P., B. Remond, and M. Theriez. 1980. Ingestive behaviour and related activities in ruminants. In: Y. Ruckebusch and P. Thivend (Ed.) Digestive Physiology and Metabolism in Ruminants. AVI Publishing Company, Connecticut.

Engelman, R. and P. LeRoy. 1995. Conserving land: Population and sustainable food production. Population Action International.

Fahey, G.C, M. Collins, D.R. Mertens, and L.E. Moser. 1994. Forage Quality, Evaluation, and Utilization. American Society of Agronomy Inc., Crop Science Inc., Society of America, Soil Science Society of America, Inc. Madison, WI.

Felton, E.E.D. and M.S. Kerley. 2003. Intrinsic factors affecting forage intake and digestibility: Evaluation of current and future methods of determination. Symposium proceedings of the Mid West AOAC/NFTA Meeting.

Fisher, D.S. 2002. A review of a few key factors regulating voluntary feed intake in ruminants. Crop Science. 42: 1651-1655.

Fontenot, J.P., V.G. Allen, and F.P. Horn. 1985. Forages and Slaughter Cattle. In: M.E. Heath, R.F. Barnes, D.S. Metcalfe (ed). Forages: The Science of Grassland and Agriculture. P 570. Iowa State University Press, Ames, lowa.

Forbes, J.M. 1996. Integration of regulatory signal controlling forage intake in ruminants. J. Anim. Sci. 74: 3029- 3035.

Forbes, J.M. and F.D. Provenza. 2000. Integration of learning and metabolic Signals into a theory of dietary choice and food intake. In: P.B. Cronje 
(Ed.) Ruminant Physiology: Digestion, Metabolism, Growth, and, Reproduction. CAB International, New York.

Fu, C.J., E.E.D. Felton, J.W. Lehmkuhler, and M.S. Kerley. 2001. Ruminal Peptide concentration required to optimize microbial growth and Efficiency. J. Anim. Sci. 79: 1305-1312.

Galyean, M.L. 1997. Laboratory procedures in animal nutrition research. Available: http://www.asft.ttu.edu/home/mgalyean/lab man.pdf. Accessed March 23, 2005.

Gekara, O.J., E.C. Prigge, W.B. Bryan, M. Schettini, E.L. Nestor, and E.C. Townsend. 2001. Influence of pasture sward height and concentration supplementations on intake digestibility, and grazing time of lactating beef cows. J. Anim. Sci. 79: 745-752.

Goering, H.K. and P.J. Van Soest. 1970. Forage fiber analysis. USDA. Agriculture Research Service. Handbook. Number 379.

Grovum, W.L. 1988. Appetite, palatability, and control of feed intake. In: D.C. Church (Ed) The Ruminant Animal: Digestive Physiology and Nutrition. P 202. Waveland Press, Inc. Illinois.

Hall, M. H. 1992. Ryegrass. Agronomy Facts \#19. Pennsylvania State College of Agricultural Sciences.

Hall, M. H. 1994a. Orchardgrass. Agronomy Facts \#25. Pennsylvania State College of Agricultural Science.

Hall, M. H. 1994b. Reed Canarygrass. Agronomy Facts \#26. Pennsylvania State College of Agricultural Sciences.

Hall, M. H. 1994c. Smooth Bromegrass. Agronomy Facts \#27. Pennsylvania State College of Agricultural Sciences.

Hall, M. H. 1994d. Tall Fescue. Agronomy Facts \#28. Pennsylvania State College of Agricultural Sciences.

Hall M. H. 1994e. Timothy. Agronomy Facts \#24. Pennsylvania State College of Agricultural Science.

Hall, M.H, and J. Jung. 1993. Extending the grazing season. Agronomy Facts \#41. Pennsylvania State College of Agricultural Science.

Hancock, D.L., J.E. Williams, H.B. Hedrick, E.E. Beaver, D.K. Larrick, M.R. Ellersieck, G.B. Garner, R.E. Morrow, J.A. Paterson, and J.R. Gerrish. 
1987. Performance, body composition and carcass characteristics of finishing steers as influenced by previous forage system. J. Anim. Sci. 65: 1381- 1391.

Hannaway, D.B., C. Larson, D. Myers, and M. Cool. 1999. Perennial Ryegrass. Accessed July 8, 2005. www.forages.orst.edu

Hannaway, D.B., C. Larson, D. Myers, and M. Cool. 2004. Orchardgrass. Accessed July 8, 2005. www.forages.orst.edu.

Hanson, A.A. and M.W. Evans. 1962. Timothy. In: H.D. Hughes, M.E. Heath, and D.S. Metcalfe (Eds.) Forages. The lowa State University Press. Ames, lowa.

Hart, S.P. and H.P. Glimp. 1991. Effect of diet composition and feed intake level On diet digestibility and ruminal metabolism in growing lambs. J. Anim. Sci. 69: 1636-1644.

Hatfield, P.G., J.W. Walker, J.A. Fitzgerald, H.A. Glimp, and K.J. Hemenway. 1993. The effects of different methods of estimating fecal output on plasma cortisol, fecal output, forage intake, and weight change in free ranging and confined wethers. J. Anim. Sci. 71: 618- 624.

Heath, M.E. and H.D. Hughes. 1962. Reed Canarygrass. In: H.D. Hughes, M.E. Heath, and D.S. Metcalfe (Ed.) The lowa State University Press. Ames, lowa.

Hitz, A.C., and J.R. Russell. 1998. Potential of stockpiled perennial forages in winter grazing system for pregnant beef cows. J. Anim. Sci. 76: 404- 415.

Hodgson, H.J. 1977. Gaps in knowledge and technology for finishing cattle on forages. J. Anim. Sci. 44: 896-900.

House, H.K. 2003. Housing requirements for backgrounding cattle. Ontario Ministry of Agriculture, Food, and Rural Affairs. Accessed July 16, 2005. http://www.gov.on.ca/OMAFRA/english/livestock/beef/facts/info housreq.h $\underline{\mathrm{tm}}$

Hoveland, C. S. 1986. Beef-forage systems for the southeastern United States. J. Anim. Sci. 63: 978-985.

Illius, A.W. and N.S. Jessop. 1996. Metabolic constrains on voluntary intake in ruminants. J. Anim. Sci. 74: 3052-3062.

Illius, A.W., N.S. Jessop, and M. Gill. 2000. Mathematical models of food intake And metabolism in ruminants. In: P.B. Crohje (Ed.) Ruminant 
Physiology: Digestion, Metabolism, Growth, and Reproduction. CAB International, New York.

Journet, M. and B. Remond. 1976. Physiological factors affecting the voluntary intake of feed by cows: a review. Livestock Production Sci. 3: 129146.

Jung, H.G. and M.S. Allen. 1995. Characteristics of plant cell walls affecting intake and digestibility of forages by ruminants. J. Anim. Sci. 73: 27742790.

Kaiser, C.J. and D.B. Faulkner. 1991. Predicting animal performance from sequential grazing of various cool- warm- cool season perennial grass specie combinations. Forage and Grassland Conference. Missouri.

Karimi, A.R., F.N. Owens, and G.W. Horn. 1987. Simultaneous extraction of Yb, Dy, and Co from feces. Animal Science Research Report. P 118.

Kelman, W., M. Bugalho, and H. Dove. 2003. Cuticular wax alkanes and alcohols used as markers to estimate diet composition of sheep (Ovis aries). Biochemical Systematics and Ecology. 31: 919-927.

Ketelaars, J.J.M.H. and B.J. Tolkamp. 1996. Oxygen efficiency and the control of energy flow in animals and humans. J. Anim. Sci. 74: 3036-3051.

Kiesling, H.E., H.A. Barry, A.B. Nelson, and C.H. Herbel. 1961. Recovery of chromic oxide administered in paper to grazing steers. J. Anim. Sci. 361364.

Kotb, A.R. and T.D. Luckey. 1972. Markers in Nutrition. Nutrition Abstracts and Reviews. 42(3): 813-835.

Kozloski, G.V., E.M. de Moraes, and A.F. Martins. 1998. Use of chromium oxide in digestibility studies: Variations of the results as a function of the measurement method. J. of the Sci. of Food and Agriculture. 76: 373-376.

Lewis, J.M., T.J. Klopfenstein, G.A. Pfeiffer, and R.A. Stock. 1990. An economic evaluation of the differences between intensive and extensive beef production systems. J. Anim. Sci. 68: 2506-2516.

Lippke, H. 2002. Estimation of forage intake by ruminants on pasture. Crop Science. 42: 869-872.

Lippke, H, W.C. Ellis, and B.F. Jacobs. 1986. Recovery of indigestible fiber from feces of sheep and cattle on forage diets. J. Dairy Sci. 69: 403-412. 
Macoon, B., L.E. Sollenberger, J.E. Moore, C.R. Staples, J.H. Fike, and K. Portier. 2003. Comparison of three techniques for estimation the forage intake of lactating dairy cows on pasture. J. Anim. Sci. 81: 2357-2366.

Martin, J.H. and W.H. Leonard. 1967. Principles of Field Crop Production. The Macmillan Company, New York.

Martz, F.A., J. Gerrish, R. Belyea, and V. Tate. 1999. Nutrient content, dry matter yield, and species composition if cool season pasture with management intensive grazing. J. Dairy Sci. 82: 1538-1549.

Mayes, R.W., C.S. Lamb, and P.M. Colgrove. 1986. The use of dosed and herba herbage $\mathrm{n}$-alkanes as markers for the determination of herbage intake. J. of Agricultural Science, Cambridge. 107: 161-170.

McKenna, D.R., D.L. Roeber, P.K. Bates, D.S. Hale, D.B. Griffin, J.W. Savell, J.C. Brooks, J.B. Morgan, T.H. Montgomery, K.E. Belk, and G.C. Smith. 2002. National Beef Quality Audit- 2000: Survey of targeted cattle and carcass characteristics related to quality, quantity, and value of fed steers and heifers. J. Anim. Sci. 80: 1212-1222.

Merchen, N.R. 1988. Digestion, absorption, and excretion in ruminants. In: D.C. Church (Ed) The Ruminant Animal: Digestive Physiology and Nutrition. Waveland Press, Inc. Illinois.

Mertens, D.R. 1987. Predicting intake and digestibility using mathematical models of ruminal function. J. Anim. Sci. 64: 1548-1558.

Mertens, D.R. 1994. Regulation of forage intake. In: G.C. Fahey, Jr., M. Collins, D.R. Mertens, and L.E. Moser (Eds). Forage Quality, Evaluation, and Utilization. P 450. ASA-CSSA-SSA, Madison, WI.

Mertens, D.R. and L.O. Ely. 1979. A dynamic model of fiber digestion and passage in the ruminant for evaluating forage quality. J. Anim. Sci. 49 (4): 1085-1095.

Mertens, D.R. and L.O. Ely. 1982. Relationship of rate and extent of digestion to forage utilization- A dynamic model of evaluation. J. Anim. Sci.. 54(4): 895-905.

Momont, P.A., R.J. Pruitt, R.J. Emerick, and R.H. Pritchard. 1994. Controlled release chromic oxide and alkaline peroxide lignin marker methods. Journal of Range Management. 47: 418-423.

Myers, W.M. 1962. Orchardgrass. In: H.D. Hughes, M.E. Heath, and D.S. Metcalfe (Ed) Forages. The lowa State University Press. Ames, lowa. 
National Research Council. 1996. Nutrient Requirements of Beef Cattle. National Academy Press, Washington.

Nelson, A.B. and G.R. Green. 1961. Excretion of chromic oxide administered in paper to steers fed prairie hay. J. Anim. Sci. 365-369

Nelson, C.J. and L.E. Moser. 1994. Plant factors affecting forage quality. In: G.C. Fahey Jr., M. Collins, D.R. Mertens, and L.E. Moser (Ed) Forage Quality, Evaluation, and Utilization. P 115. ASA-CSSA-SSSA, Madison, WI.

Newell, L.C. and K.L. Anderson. 1962. Smooth Bromegrass. In: H.D. Hughes, M.E. Heath, and D.S. Metcalfe (Ed.) Forages. The lowa State Univeristy Press, Ames, lowa.

Ohajuruka, O.A. and D.L. Palmquist. 1991. Evaluation of n-alkanes as digesta markers in dairy cows. J. Anim. Sci. 69: 1726-1732.

Ohio State University Extension. 2005. Maximizing fall and winter grazing of beef cows and stocker cattle. Bulletin 872-98. Accessed July 12, 2005. http://www.caf.wvu.edu/ -forage/ohioline/index.html.

Old, C.A. and W.N. Garrett. 1987. Effects of energy intake on energetic efficiency and body composition of beef steers differing in size at maturity. J. Anim. Sci. 65: 1371-1380.

Ordakowski, A.L., D.S. Kronsfeld, J.L. Holland, B.J., Hargreaves, L.S. Gay, P.A. Harris, H. Dove, and D. Sklan. 2001. Alkanes as internal markers to estimate digestibility of hay or hay plus concentrate diets in horses. J. Anim. Sci. 79: 1516-1522.

Paterson, J., C. Forcherio, B. Larson, M. Samford, and M. Kerley. 1995. The effects of fescue toxicosis on beef cattle productivity. J. Anim. Sci. 73: 889-898.

Phillips, W.A., M.A. Brown, R.S. Gossen, W.L. Graham, J.W. Holloway, H.S. Mayeux, and L.F. Devane. 2002. Evaluation of a new system for finishing beef cattle on small farms in Oklahoma. Proceedings of the Oklahoma Acad. Science. 82: 27-33.

Pond, K.R., W.C. Ellis, W.D. James, and A.G. Deswysen. 1985. Analysis of multiple markers in nutrition research. J. Dairy Sci. 68: 745-750.

Prigge, E.C., W.B. Bryan, and E.S. Goldman-Innis. 1999. Early- and late-season grazing of orchardgrass and fescue hayfields overseeded with red clover. 
Agron. J. 91: 690-696.

Quinlan, D. J. 1994. Comparison of summer grazing management systems for beef cattle grazing big bluestem. M. S. Thesis, University of Missouri, Columbia.

Rayburn, E.B. 1992. Grazing Systems. Accessed July 16, 2005. http://www.caf.wvu.edu/ forage/5712.htm.

Rayburn, E. 2001. Extended grazing reduces winter feed costs. West Virginia Farm bureau News, WVU Update.

Reid, J.T. P.G. Woolfolk, C.R. Richards, R.W. Kaufmann, J.K. Loosli, K.L. Turk, J.I. Miller, and R.E. Blaser. 1949. A new indicator method for the determination of digestibility and consumption of forages by ruminants. J. Anim. Sci. 60-71.

Sainz, R.D. and R.F. Vernazza-Paganini. 2004. Effects of different feeding Periods on performance and carcass traits of beef steers. J. Anim. Sci.. 82: 292-297.

Smith, D. 1975. Forage Management in the North. Kendall/Hunt Publishing Company, Madison, WI.

Sunvold, G.D. and R.C. Cochran. 1991. Technical note: Evaluation of acid detergent lignin, alkaline peroxide lignin, acid insoluble ash, and indigestible acid detergent fiber as internal markers for prediction of alfalfa, bromegrass, and prairie hay digestibility by beef steers. J. Anim. Sci. 69: 4951- 4955.

Taylor, T.H. and W.C. Templeton, jr. 1976. Stockpiling Kentucky bluegrass And tall fescue forage for winter pasturage. Agronomy Journal. 68: 235239.

Tjardes, K.E., D.D. Buskirk, M.S. Allen, N.K. Ames, L.D. Bourquin, and S.R. Rust. 2002. Neutral detergent fiber concentration of corn silage and rumen inert bulk influences dry matter intake and ruminal digesta kinetics of growing steers. J. Anim. Sci.. 80: 833-840.

Turner, H.A., and R.J. Raleigh. 1977. Production of slaughter steers from forages in the arid west. J. Anim. Sci. 44: 901-907.

Van Keulen, J. and B.A. Young. 1977. Evaluation of acid insoluble ash as a natural marker in ruminant digestiblity studies. J. Anim. Sci. 44: 282-287.

Van Saun, R.J. 2005. Understanding Ruminant Nutrition: Feeding for two. 
Accessed July 12, 2005.

http://www.vetmed.wsu.edu/courses-jmgay/documents/FeedingFor2.doc.

Van Soest, P.J. 1965. Symposium on factors influencing the voluntary intake of herbage by ruminants: Voluntary intake in relation to chemical composition and digestibility. J. Anim. Sci. 24: 834-842.

Van Soest, P.J. 1967. Development of a comprehensive system of feed analysis and its application to forages. J. Anim. Sci. 26: 119-128.

Van Soest, P.J., J.B. Robertson, and B.A. Lewis. 1991. Methods for dietary fiber, neutral detergent fiber, and non-starch polysaccharides in relation to animal nutrition. J. Dairy Sci. 74: 3583-3597.

Van Soest, P.J. 1994. Intake. In: Nutritional Ecology of the Ruminant. P 337-353. Cornell University Press. Ithaca, NY.

Vicini, J.L., E.C. Prigge, W.B. Bryan, and G.A. Varga. 1982. Influence of forage species and creep grazing on a cow-calf system. I. Intake and digestibility of forages. J. Anim. Sci. 55: 752-758.

Weather Underground. http://www.wunderground.com/

Welch, J.G. 1967. Appetite control in sheep by indigestible fiber. J. Anim. Sci. 26: 849.

Welch, J.G. 1986. Physical parameters of fiber affecting passage rate from the Rumen. J. Dairy Sci. 69: 2750-2754.

Welch, J.G. and A.P. Hooper. 1988. Ingestion of feed and water. In: The Ruminant Animal: Digestive Physiology and Nutrition. D.C. Church (Ed.) P 115. Waveland Press, Inc. Illinois.

Young, B.A. 1977. The effect of climate upon intake. In: J.B. Hacker and J.H. Ternouth (Ed) The Nutrition of Herbivores. P 163. Academic Press, New York.

Zinn, R.A. and R.A. Ware. 2003. Understanding nutritive value: Alternative Forages. Accessed July 12, 2005. www.alfalfa.ucdavis.edu/symposium/2003/procl. 